\title{
Os Estados de Bem-Estar Social da Europa Ocidental: tipologias, evidências e vulnerabilidades *
}

\author{
Paulo José Whitaker Wolf ** \\ Giuliano Contento de Oliveira ***
}

\begin{abstract}
Resumo
Este artigo tem o objetivo de analisar as principais características dos Estados de Bem-Estar Social da Europa Ocidental, bem como as principais diferenças existentes entre eles. Esses arranjos devem ser entendidos como uma dentre as formas possíveis de sistemas de proteção social e que se caracteriza pelo fato de que o Estado assume um papel mais contundente no atendimento das necessidades fundamentais dos indivíduos relativamente às demais formas de provisão, como o mercado e a família. Esses arranjos se diferenciam em função do perfil das políticas públicas, em geral, e das políticas econômica e social, em particular. Esse perfil é determinado pelo processo de interação entre grupos com diferentes preferências e com diferentes capacidades de impor essas preferências sobre os demais em determinadas circunstâncias históricas. Os regimes estudados mostram que arranjos mais sofisticados são mais factíveis e resilientes em sociedades menos heterogêneas, isto é, com clivagens menores do ponto de vista material e imaterial. Concluiu-se que os países da Europa Ocidental cujas políticas públicas são caracterizadas por uma política social preventiva, bem como por uma maior articulação dessa política com a política econômica, com maior grau de autonomia para se ajustar às exigências de cada situação, estão mais bem preparados que os demais para assegurar a proteção da dignidade humana diante dos desafios impostos pelo capitalismo contemporâneo.
\end{abstract}

Palavras-chave: Estados de Bem-Estar Social; Tipologias; Europa Ocidental; Sistemas de proteção social; Políticas públicas.

\section{Abstract \\ Western European welfare states: typologies, evidences, and vulnerabilities}

This paper aims to analyze the main characteristics of Western European welfare states, as well as the main differences that exist between them. These arrangements are to be understood as one form among the possible forms of social protection systems and that is characterized by the fact that the state assumes a more forceful role in meeting individual fundamental needs compared to other forms of welfare provision, such as the market and the family. These arrangements differ according to the profile of public policies, in general, and of economic and social policies, in particular. This profile is determined by the process of interaction between groups with different preferences and different capabilities to impose these preferences on other groups in certain historical circumstances. The regimes analyzed show that more sophisticated arrangements are more feasible and resilient in societies with less heterogeneities, i.e., with smaller cleavages from the material and immaterial point of view. The paper concludes that the Western European countries whose public policies are characterized by a

* Artigo recebido em 31 de agosto de 2015 e aprovado em 20 de setembro de 2016.

** Doutorando em Economia no Instituto de Economia da Universidade Estadual de Campinas (IE/Unicamp) / Pesquisador do Centro de Estudos de Relações Econômicas Internacionais (eri), Campinas, SP, Brasil. E-mail: paulowwolf@gmail.com.

*** Professor do Instituto de Economia da Unicamp, Campinas, SP, Brasil. E-mail: giueco@unicamp.br. 
preventive social policy, as well as by a greater coordination of this policy with economic policy, which has a higher grade of autonomy to act according to each situation, are better prepared than others to assure the protection of human dignity in the face of challenges posed by contemporary capitalism.

Keywords: Welfare states; Typologies; Western Europe; Social Protection Systems; Public Policies. JEL I00, I30, I31, I38, F5.

\section{Introdução}

Ao discutir as origens de nossa época, Polanyi (1944) mostrou o efeito que o capitalismo é capaz de exercer sobre os indivíduos e a sua natureza humana. Sem intervenção, os seres humanos são transformados em meras engrenagens de um sistema movido pela lógica da acumulação de riqueza em sua forma mais geral e abstrata. Ao invés de emancipar os homens, aprisiona-os e submete-os a processos imprevisíveis como uma força que lhes é, ao mesmo tempo, estranha e irresistível. Eles são lançados em um contexto de enorme insegurança. Por isso a necessidade de mecanismos para proteger a sociedade.

Nesta perspectiva, este artigo se debruça sobre um destes mecanismos de proteção criados pela sociedade, a saber, os Estados de Bem-Estar Social. Durante a segunda metade do século XX, diversos países da Europa Ocidental construíram algum tipo desses arranjos, o que certamente influenciou as condições de vida prevalecentes em cada um deles.

Destarte, o objetivo deste artigo consiste em analisar as principais características dos Estados de Bem-Estar Social de regiões selecionadas da Europa Ocidental, as principais diferenças existentes entre eles, bem como as suas principais causas e consequências dessas diferenças para as sociedades em que eles surgiram e se desenvolveram. Argumenta-se que os Estados de Bem-Estar Social possuem um importante papel a cumprir na proteção da dignidade humana, mas que alguns arranjos são mais capazes do que outros de fazer isso diante dos desafios impostos pelo capitalismo contemporâneo. Sustenta-se, pois, que essa capacidade diferenciada está intimamente relacionada ao perfil das políticas públicas, em geral, e das políticas econômica e social, em particular, o qual depende das características dos processos políticos em cada sociedade e momento, isto é, das relações de poder entre grupos com diferentes preferências em circunstâncias históricas específicas.

Para isso, o artigo foi dividido em cinco seções, além desta introdução e da conclusão. A seguir, discute-se o que são os Estados de Bem-Estar Social e a sua pertinência no sistema capitalista. Depois disso, são consideradas as diferenças existentes entre esses arranjos a partir de tipologias, tendo-se em vista a experiência de países selecionados da Europa Ocidental ${ }^{1}$. Em seguida, verifica-se como essas

(1) Esses arranjos serão considerados neste artigo em sua forma atual, isto é, após as transformações sofridas por eles desde o seu surgimento. O caso do Reino Unido, por exemplo, é bastante emblemático nesse 
diferenças se manifestam e de que forma elas afetam as condições de vida prevalecentes em cada tipo ideal por meio da análise de dados e indicadores selecionados. Por fim, são consideradas algumas das principais fontes de pressão a que estão sujeitos esses arranjos atualmente.

\section{Noções fundamentais sobre o Estado de Bem-Estar Social}

Os Estados de Bem-Estar Social devem ser entendidos como institucionalidades capazes de intervir nos processos de produção e distribuição da riqueza. Idealmente, busca-se, com essas institucionalidades, proteger os indivíduos contra aquilo que limita a sua capacidade de atender as necessidades fundamentais, isto é, aquelas associadas às diferentes fontes de insegurança as quais está sujeita a vida no capitalismo. Trata-se, pois, de um dever do Estado e um direito dos indivíduos, decorrente da sua condição de $\operatorname{cidadãos}^{2}$ (Marshall, 1950).

A concepção de cidadania subjacente a esses arranjos contrasta com as noções de contrato e de caridade. Isso quer dizer que a proteção da dignidade humana é concebida como algo que não possui um preço, tampouco é passível de negociação. Também não depende da benevolência daqueles suficientemente altruístas para se compadecer do sofrimento alheio, prestando-lhe assistência gratuita e desinteressada. De fato, a noção de cidadania fundamenta-se na solidariedade que emerge do reconhecimento de que todos são mutuamente dependentes e de que, nesse caso, todos têm a ganhar atuando cooperativamente (Baldwin, 1990).

Dessa forma, os Estados de Bem-Estar Social nada mais são do que uma dentre as várias formas possíveis de sistema de proteção social, caracterizando-se pelo fato de que o Estado assume um papel mais contundente no atendimento das necessidades individuais fundamentais relativamente às demais formas de provisão, como o mercado e a família. Nesse caso, ele pressupõe um processo de desmercantilização, isto é, de redução do grau de dependência dos indivíduos em relação ao mercado para a preservação de seus direitos fundamentais, na condição de cidadãos. Isso significa a reversão do processo de reificação dos homens e das relações sociais que se estabelecem entre eles, dado que a sua sobrevivência não mais depende da compra e venda da força de trabalho para obter em troca aquilo de que necessitam. Ele pressupõe também um processo de desfamiliarização, ou seja, de redução do grau de dependência dos indivíduos em relação à família. Isso não

sentido. O país, que no contexto da "era de ouro" do capitalismo se aproximava do perfil do modelo escandinavo, foi assumindo progressivamente o perfil do modelo anglo-saxão, sendo mais apropriado, atualmente, classificá-lo como tal.

(2) Essas necessidades podem ser decorrentes de fatores naturais, surgindo da condição dos indivíduos enquanto seres humanos, mas também decorrentes de fatores sociais, surgindo da condição dos indivíduos enquanto seres humanos membros da sociedade. Enquanto as necessidades naturais tendem a ser aespaciais e atemporais, as necessidades sociais tendem a variar, tanto no espaço como no tempo (Titmuss, 1963). 
significa uma redução do seu papel na formação da identidade individual, bem como na organização da vida social, enquanto principal mecanismo de transmissão das regras e normas que orientam esses processos, mas apenas que os laços de solidariedade entre os indivíduos não mais se restringem aos "laços de sangue" (Di Giovanni, 1998; Esping-Andersen, 1990, 1999).

Esse papel do Estado no atendimento das necessidades individuais fundamentais está intimamente relacionado ao perfil das políticas públicas, vale dizer, a forma por meio da qual ele é capaz de intervir sobre a realidade com o intuito de preservá-la ou modificá-la em determinado sentido. Evidentemente, as políticas públicas pressupõem uma capacidade mínima de conceber e implementar decisões por parte do Estado, tanto no que se refere à disponibilidade de recursos humanos e financeiros, como no que diz respeito à sua legitimidade.

Dentre as políticas públicas, destacam-se as políticas econômica e social, pois ambas reúnem os principais instrumentos por meio dos quais o Estado é capaz de afetar as condições materiais e, assim, fazer com que os indivíduos possam atender as suas necessidades fundamentais. Mais especificamente, elas influenciam a capacidade dos indivíduos de obter um rendimento e de convertê-lo em um conjunto de bens e serviços considerados essenciais, de acordo com os padrões que prevalecem em uma dada sociedade em cada momento ${ }^{3}$ (Di Giovanni, 2009).

Por sua vez, o perfil das políticas públicas é o resultado de um processo político, isto é, de um processo de interação entre grupos com diferentes preferências e com diferentes capacidades de impor essas preferências sobre os demais, sendo que essas preferências nada mais são do que a forma como os interesses se manifestam na prática. De fato, enquanto os interesses se referem às motivações dos indivíduos, as preferências se referem às escolhas que eles fazem para atender aqueles interesses. Dessa forma, as políticas públicas resultam da correlação de forças entre os diferentes grupos que compõem uma dada sociedade em um determinado momento histórico, sendo a materialização dos interesses dos grupos mais poderosos em cada contexto.

É importante ressaltar que, embora esses grupos estejam inevitavelmente relacionados às suas respectivas classes sociais, na medida em que os indivíduos que as compõem partilham de determinadas características comuns, o perfil das políticas públicas é determinado fundamentalmente pelo processo de interação entre frações de classe, uma vez que, mesmo dentro de uma classe social, pode haver preferências diferentes, a depender da situação sobre a qual os indivíduos que as compõem são chamados a se posicionar.

(3) A política econômica contempla as políticas fiscal, monetária, cambial, comercial e de rendas. Já a política social reúne os instrumentos que asseguram o acesso a um rendimento ou a um conjunto de bens e serviços essenciais. 
Evidentemente, esse processo de interação entre atores não ocorre no "vácuo". Ao contrário, ele se desenvolve no âmbito de circunstâncias históricas específicas, as quais são capazes de alterar não apenas as preferências dos grupos sociais em interação, mas também a correlação de forças entre eles. Deve-se observar que as circunstâncias históricas se referem não apenas ao conjunto de eventos econômicos, sociais e políticos que se desenvolve em dada sociedade em determinado momento, mas também ao conjunto de normas e regras, mais ou menos formais, que orienta a vida social, isto é, às instituições (Ikenberry, 1994).

As instituições, por seu turno, são construções sociais transmitidas de geração em geração e que definem a identidade de um povo. Elas tendem a ser resistentes, alterando-se muito lentamente ao longo do tempo, de modo que é por meio delas que o passado é capaz de afetar o presente e este é capaz de afetar o futuro, atribuindo um elemento de continuidade, ou, ainda, de inércia, ao perfil da ação do Estado. Decisões tomadas pelos atores em um determinado momento são transportadas no tempo e condicionam as suas possibilidades de ação nos momentos subsequentes, e assim sucessivamente. Daí decorre, inclusive, a noção de "dependência de trajetória" (path dependence), ou seja, a noção de que trajetórias que antes eram igualmente possíveis tornam-se cada vez menos prováveis à medida que se avança em uma delas. Isso porque elas criam raízes profundas na sociedade, de modo que é mais fácil permanecer em uma dada trajetória do que alterá-la radicalmente em um ou outro sentido (Wilsford, 1994; Pierson, 2000).

Além disso, o perfil das políticas públicas é fortemente influenciado pela ideologia. De fato, ao defender os seus interesses, os grupos sociais em interação se apoiam em um determinado conjunto de ideias, ou, ainda, em uma determinada interpretação a respeito do funcionamento do mundo em que eles estão inseridos em verdade, uma representação de um todo complexo construída por meio de processos cognitivos. É justamente a partir desse conjunto de ideias que esses grupos sociais decidem a melhor forma de atuar sobre a realidade, formando as suas preferências tendo em vista atender os seus interesses. Em geral, as ideias são impostas pelos grupos mais fortes sobre os grupos mais fracos com o próprio objetivo de ocultar essa relação de hierarquia e, dessa forma, assegurar a sua reprodução. De fato, a ideologia pode mascarar os aspectos controversos dessa interação e, assim, evitar o seu questionamento e facilitar a sua aceitação (Bobbio, 1998; Di Giovanni, 2013). A esse respeito, afirmou Keynes (1936, p. 291):

[...] as ideias dos economistas e filósofos políticos, estejam elas certas ou erradas, têm mais importância do que geralmente se percebe. De fato, o mundo é governado por pouco mais do que isso. Os homens objetivos que se julgam livres de qualquer influência intelectual são, em geral, escravos de algum economista defunto. Os insensatos, que ocupam posições de autoridade, que ouvem vozes no ar, destilam seus arrebatamentos inspirados em algum escriba 
acadêmico de certos anos atrás. Estou convencido de que a força dos interesses escusos se exagera muito em comparação com a firme penetração das ideias. É natural que elas não atuem de maneira imediata, mas só depois de certo intervalo [...]. Porém, cedo ou tarde, são as ideias, e não os interesses escusos, que representam um perigo, seja para o bem ou para o mal.

Nesse contexto, os Estados de Bem-Estar Social pressupõem o entendimento de que os indivíduos, ao agir de acordo com os seus interesses, não necessariamente são levados a assegurar o melhor resultado para si e para os outros. Isso porque existe uma contradição entre a busca do enriquecimento privado e a criação de nova riqueza para a sociedade no capitalismo, na medida em que o desejo de acumular riqueza em sua forma mais geral e abstrata pode se tornar antissocial, sobretudo em contextos em que se radicaliza a incerteza a respeito de um futuro incognoscível. De fato, deixado livre para atuar de acordo com a sua própria lógica, o capitalismo não é capaz de assegurar a maior produção e, principalmente, a melhor distribuição de riqueza, de modo que nem a todos é assegurada a possibilidade de atender as suas necessidades fundamentais. Nesse caso, o Estado possui um importante papel a cumprir, por meio das políticas públicas (Keynes, 1926, 1936; Belluzzo; Almeida, 1999; Belluzzo, 2004; Carvalho, 2008).

Assim, a política econômica e a política social devem ser administradas em conjunto, de sorte a assegurar a todos a possibilidade de contribuir e partilhar da riqueza socialmente produzida. De um lado, elas devem garantir a plena utilização dos recursos disponíveis e o aumento da capacidade produtiva. De outro, elas devem assegurar que o resultado do esforço comum se reparta de tal forma que assegure a todos a possibilidade de viver uma vida em condições civilizadas, ou seja, de acordo com os padrões que prevalecem em dada sociedade em cada momento histórico. De fato, porque atuam sobre a mesma realidade, ainda que por meio de instrumentos diferentes, a política econômica e a política social devem atuar de forma coordenada, a fim de se reforçarem mutuamente. Enquanto a política econômica deve ser flexível o suficiente para ser ajustada às exigências de cada situação, a política social deve ser estendida para toda a sociedade, garantido os direitos dos cidadãos.

Nesse contexto, deve-se observar que a garantia de uma vida civilizada a todos os indivíduos de uma sociedade não necessariamente pressupõe o comprometimento da capacidade da economia de gerar nova riqueza. Ao contrário, ela pode exercer um papel importante nesse processo. Isso quer dizer, portanto, que os Estados de Bem-Estar Social não pressupõem um trade-off inequívoco entre igualdade e eficiência, desde que os instrumentos por meio dos quais o Estado pode intervir na realidade sejam manejados de forma apropriada, de sorte a promover sinergias capazes de assegurar a maior produção e a melhor distribuição da riqueza possíveis. Nesse caso, esses arranjos devem ser entendidos, antes de tudo, como 
parte de uma estratégia de desenvolvimento em seu sentido econômico e social (Esping-Andersen, 1992).

\section{Os quatro modelos de Estado de Bem-Estar Social da Europa Ocidental}

Como visto, os Estados de Bem-Estar Social possuem como denominador comum a assunção, pelo Estado, da responsabilidade de proteger os membros da sociedade contra aquilo que ameaça a sua capacidade de atender as suas necessidades fundamentais e, assim, de viver uma vida civilizada, por meio de um conjunto de políticas concebidas e implementadas deliberadamente para esse fim. Entretanto, esses arranjos variam quanto ao papel assumido pelo Estado relativamente às demais formas de provisão e, consequentemente, quanto ao perfil dessas políticas.

Isso é particularmente evidente no caso dos países da Europa Ocidental. Foi nessa região do mundo que os Estados de Bem-Estar Social surgiram e se desenvolveram primeiro, tornando-se uma referência para experiências de natureza semelhante em outras regiões. Esses arranjos, entretanto, variam consideravelmente entre si. De fato, eles assumiram diferentes graus de sofisticação de acordo com as especificidades de cada sociedade em determinado contexto histórico.

Nesse caso, os Estados de Bem-Estar Social da Europa Ocidental serão considerados a seguir a partir de tipologias, isto é, a partir de tipos-ideais construídos por meio da identificação de características comuns às experiências nacionais e da supressão de elementos dissidentes, supondo que estes não constituem a essência dessas experiências. Esses tipos-ideais são casos abstratos e que, enquanto tal, tornam-se parâmetros em relação aos quais os casos concretos podem ser contrastados ${ }^{4}$.

\subsection{Tipologias}

As tipologias apresentadas de Estados de Bem-Estar Social são um retrato desses arranjos em um determinado momento do tempo, como no caso atual em questão, não revelando, portanto, as transformações pelas quais esses modelos têm passado ao longo da história. De fato, nenhum desses arranjos permaneceu imune a alguma forma de transformação desde que eles surgiram no contexto posterior à Segunda Guerra Mundial. Em alguns casos, essas mudanças foram tão profundas que os levaram a transitar de um tipo-ideal para outro. Não constitui objetivo deste artigo, contudo, considerar essas transformações em detalhes, mas sim capturar os

(4) Tipos-ideais, na concepção weberiana, são instrumentos de análise cujo intuito é permitir a compreensão da realidade em sua diversidade. Eles são modelos construídos a partir da identificação de determinados padrões, ou, ainda, regularidades, no âmbito de diferentes fenômenos sociais complexos. Com efeito, um tipo é considerado "ideal” não porque ele reflete uma determinada concepção do que é desejável, mas porque eles são representações da realidade construídas no mundo das ideias (Weber, 1949). 
traços distintivos fundamentais dos diferentes modelos de Estado de Bem-Estar Social da Europa Ocidental, tal como eles se manifestam atualmente.

Partindo da tipologia originalmente concebida por Titmuss (1974), EspingAndersen $(1990,1999)$ propôs a existência de três modelos de Estado de Bem-Estar Social, a saber: i) liberal; ii) conservador-corporativo; e iii) socialdemocrata. Para o caso específico dos países da Europa Ocidental, esses arranjos podem ser denominados como, respectivamente: i) anglo-saxão; ii) continental; e iii) escandinavo. Para tanto, o autor considerou não apenas quanto dinheiro é gasto por esses arranjos, mas como ele é gasto e que resultados ele produz.

Não obstante, ajustes são necessários nessa tipologia, de modo a assegurar uma representação mais adequada da realidade. Isso porque a construção de três modelos de Estado de Bem-Estar Social não parece ser suficiente para fazer frente à variedade de arranjos existentes na Europa Ocidental, considerando os países selecionados. Mais especificamente, embora esses modelos sejam adequados para representar a realidade dos países da Europa Setentrional, eles acabam por desconsiderar a realidade dos países da Europa Meridional. De fato, tal como ressalta Ferrera (1996), existem razões suficientes para supor que esses países apresentam arranjos cujas características comuns são diferentes daquelas encontradas em outras regiões do continente, de modo que elas devem compor um quarto modelo de Estado de Bem-Estar Social, qual seja, o modelo mediterrâneo ${ }^{5}$.

As diferenças existentes entre os Estados de Bem-Estar Social dos países da Europa Setentrional e da Europa Meridional se verificam já na origem desses arranjos. No caso dos modelos anglo-saxão, continental e escandinavo, a maioria dos países concluiu os seus sistemas de proteção social no contexto do pós-guerra, ainda que os seus fundamentos sejam bastante anteriores a isso. Já no caso dos países mediterrâneos, a maioria desses arranjos assumiu a maturidade apenas na década de 1970, depois do fim de regimes autoritários: o de Franco, na Espanha; o de Salazar, em Portugal; e o de Papadopoulos, na Grécia. Nesses casos, a expansão dos direitos civis e políticos foi acompanhada pela expansão sem precedentes dos direitos sociais. Vale lembrar que esses avanços ocorreram em um contexto de considerável atraso econômico e social, relativamente aos demais países da Europa Ocidental. Ali, talvez mais do que em qualquer outra região europeia, o choque entre tradição e modernidade ocorreu de forma rápida e pronunciada, produzindo um impacto bastante profundo em todos os âmbitos da vida social (Flora; Heidelheimmer, 1981; Judt, 2008).

Além disso, deve-se observar que as instituições do Estado são menos desenvolvidas nos países mediterrâneos, relativamente aos demais países da Europa

(5) Para uma revisão do "estado da arte" no que se refere às diferentes tipologias existentes para os Estados de Bem-Estar Social, ver Arts e Gelissen (2002). 
Ocidental. Herança do período autoritário, a burocracia é excessivamente ampla e complexa e, por essa razão, frequentemente também pouco eficiente, embora em graus diferenciados entre os países que compõem a região. Além de reduzir a capacidade do Estado de conceber e implementar políticas públicas, esse tipo de arranjo viabiliza as condições para abusos, os quais reduzem a eficácia dessas ações (Ferrera, 1996).

Deve-se observar que essas tipologias são construídas sobre o perfil de apenas uma das formas de intervenção do Estado na realidade, qual seja, a política social. Nesse caso, eles atribuem maior ênfase a apenas a um dos mecanismos por meio dos quais o Estado pode afetar as condições materiais, sendo o outro instrumento a política econômica. Embora o seu perfil tenha variado consideravelmente ao longo do tempo, é possível identificar uma tendência importante. Em quase todos os países da Europa Ocidental que compõem da União Europeia, houve uma substancial reorientação da política econômica. Ela deixou de constituir um meio para influenciar a renda e o emprego e passou a ser voltada fundamentalmente para a manutenção de uma taxa de inflação baixa e estável. Isso, por sua vez, implicou uma transição de políticas discricionárias e, portanto, mais flexíveis, para políticas baseadas em regras e, assim, mais rígidas.

Esse constrangimento é particularmente acentuado no caso dos países participantes do projeto de integração regional europeu, a mais ousada iniciativa nesse sentido da história. Isso porque o desenvolvimento do mercado comum impôs a necessidade de esses países coordenarem as suas políticas econômicas. Além disso, a maioria desses países avançou em direção à união monetária ${ }^{6}$. Por essa razão, vale salientar, neste artigo foram analisados os modelos de Estados de Bem-Estar Social do conjunto de países da Europa Ocidental que hoje integram a União Europeia.

Destarte, na impossibilidade de se recorrer à política econômica, a política social tornou-se o principal mecanismo por meio do qual o Estado é capaz de proteger os indivíduos dos caprichos da "mão invisível” do mercado nos países da

(6) O euro foi criado em janeiro de 1999 e passou a circular dois anos depois, em 2002. Dentre os países restantes, alguns não se qualificaram para adotá-lo, enquanto outros optaram por preservar as suas antigas moedas, como é o caso do Reino Unido, mas também da Dinamarca e da Suécia. Ao adotar o euro, esses países transferiram a responsabilidade pela política monetária e cambial para o Banco Central Europeu, uma instituição independente cujo objetivo é a manutenção da estabilidade dos níveis de preços. Já a política fiscal permaneceu sob responsabilidade dos governos nacionais, ainda que sujeita às regras do Pacto de Estabilidade e Crescimento (PEC), que exige o comprometimento com a disciplina orçamentária ao longo do ciclo de negócios, ao impor limites para o déficit público e para a dívida pública desses países. O objetivo, com isso, era assegurar a submissão da política fiscal às diretrizes das políticas monetária e cambial definidas pelo BCE. O BCE busca uma taxa de inflação anual de aproximadamente $2 \%$, o que é feito por meio do manejo da taxa de juros de curto prazo. A instituição também realiza intervenções no mercado de divisas, de sorte a influenciar a cotação do euro em relação às demais moedas. Por sua vez, o PEC exige que os países evitem déficits públicos superiores a $3 \%$ do PIB e dívidas públicas superiores a $60 \%$ do PIB. A rigor, os países que, por algum motivo, desrespeitassem os limites estabelecidos, estariam sujeitos a sanções, caso não implementassem medidas corretivas. 
Europa Ocidental, especialmente no caso daqueles que integram a União Europeia e adotam a moeda única, o euro. Na prática, isso implica uma pressão ainda maior sobre esses instrumentos - uma responsabilidade, frequentemente, muito superior àquela para a qual eles foram originalmente concebidos.

Nessa perspectiva, considerando-se os trabalhos de Esping-Andersen (1990, 1999) e Ferrera (1996), assume-se que os países da Europa Ocidental podem ser divididos em quatro modelos, os quais se diferenciam entre si em função do papel assumido pelo Estado no que se refere à proteção social. Isso implica um determinado grau de independência dos indivíduos em relação ao mercado e à família como mecanismo de provisão, o que, por sua vez, resulta em um certo grau de coesão social, ou seja, de diferenciação entre esses indivíduos no que se refere às suas condições de vida. São eles, então, considerando-se os países da Europa Ocidental que hoje integram a União Europeia: i) os países anglo-saxões (Irlanda e Reino Unido) ${ }^{7}$; ii) os países continentais (Alemanha, Áustria, Bélgica, França, Luxemburgo e Países Baixos); iii) os países escandinavos (Dinamarca, Finlândia e Suécia); e iv) os países mediterrâneos (Espanha, Grécia, Itália e Portugal).

\subsection{As características principais dos modelos de Estado de Bem-Estar Social}

Como visto, as diferenças entre os Estados de Bem-Estar Social estão associadas às diferenças no perfil das políticas públicas. Este, por sua vez, guarda relação com o processo de interação entre grupos com diferentes preferências e com diferentes capacidades de impor essas preferências sobre os demais em determinadas circunstâncias históricas. Essas preferências, por seu turno, dependem da forma como cada um desses grupos percebe as consequências possíveis desses arranjos, isto é, os seus benefícios e custos. Nesse sentido, pode-se afirmar que esses arranjos tendem a ser mais prováveis e resilientes em sociedades menos heterogêneas, isto é, com clivagens menores do ponto de vista material e imaterial, uma vez que, nesse caso, os seus benefícios e custos se distribuem de forma menos assimétrica entre os diferentes grupos que as compõem ${ }^{8}$. As diferentes características assumidas pelos

(7) No pós-guerra, o Reino Unido criou o mais sofisticado Estado de Bem-Estar Social entre todos os países europeus a partir das diretrizes estabelecidas pelo Plano Beveridge, de 1942. Entretanto, nas décadas seguintes, os britânicos não apenas não acompanharam os desenvolvimentos em curso nos demais países europeus, como foram os primeiros a adotar um conjunto de reformas orientadas pelos princípios liberais. Como consequência, o país, que antes se aproximava do perfil do modelo escandinavo, aproximou-se consideravelmente do perfil do modelo anglosaxão.

(8) Uma vez que a maioria desses grupos possuem motivos para considerar esses arranjos vantajosos, uma mudança na correlação de forças entre eles levará a ajustes apenas residuais em suas políticas, uma vez que eles tenham surgido. De fato, maior tenderá a ser, nesses casos, o sentimento de solidariedade recíproca e, por extensão, a disposição desses grupos em assumir compromissos de proteção mútua. 
modelos de Estado de Bem-Estar Social na Europa Ocidental, indicadas a seguir, ratificam essa hipótese? .

O modelo anglo-saxão, por exemplo, caracteriza-se pelo papel residual do Estado, o qual se restringe a assegurar o pleno funcionamento do sistema e o atendimento das necessidades fundamentais de grupos sociais específicos, notadamente aqueles que não são capazes de sobreviver por seus próprios meios. Os benefícios básicos compreendem um conjunto restrito de riscos e são bastante modestos, sendo que a maior parte deles depende da comprovação da necessidade, via teste de meios, e é financiada por meio de impostos. Aos demais grupos sociais, cabe recorrer a outras formas de provisão, como a família e, principalmente, o mercado, contando, para isso, com incentivos do próprio Estado, sobretudo por meio de isenções fiscais. Espera-se, com isso, estimular o esforço e a responsabilidade individuais e, dessa forma, evitar a cultura da dependência. Esse modelo é caracterizado, ainda, por um reduzido grau de regulamentação do mercado de trabalho e pela ausência de medidas de estímulo à oferta e demanda por trabalho. Com efeito, o modelo anglo-saxão implica reduzidos graus de desmercantilização e desfamiliarização, o que resulta em um baixo grau de coesão social, com níveis elevados de miséria e de pobreza, bem como de desigualdades sociais, relativamente aos demais modelos.

Já no regime continental, o Estado assume um papel mais importante que o mercado, mas menos importante que a família, como mecanismo de atendimento das necessidades individuais fundamentais. Os benefícios básicos compreendem um conjunto razoável de riscos e variam de acordo com a ocupação, o que atribui a esse modelo um forte caráter corporativo. O objetivo, com isso, é preservar as diferenças de status entre os indivíduos, o que lhe confere também um forte caráter conservador. $\mathrm{O}$ acesso a esses benefícios depende do pagamento de contribuições, que são o principal mecanismo de financiamento desses arranjos. Tradicionalmente, esse modelo é caracterizado por um elevado grau de regulamentação do mercado de trabalho, visando assegurar o emprego estável do homem, que, então, deveria atender às suas necessidades e de sua família por meio do seu salário e dos seus benefícios. Mais recentemente, iniciou-se um processo de flexibilização da legislação trabalhista, sobretudo no que se refere aos empregos de menor estabilidade e menores salários, o que levou a um aumento da parcela da sociedade em situação de vulnerabilidade e que passou a depender dos mecanismos de assistência pública, estes até então pouco desenvolvidos. Entrementes, o modelo continental implica um grau médio de desmercantilização e um grau reduzido de desfamiliarização, o que resulta em um grau intermediário de coesão social, com níveis médios de miséria e de pobreza, bem como de desigualdades sociais.

(9) Para uma discussão detalhada das características destes modelos, ver Wolf (2015). 
O modelo escandinavo, por seu turno, caracteriza-se pelo papel central do Estado relativamente ao mercado e à família como mecanismo de provisão do bemestar social. Os benefícios básicos compreendem um conjunto amplo de riscos e são elevados. $\mathrm{O}$ acesso a esses benefícios independe do pagamento de contribuições, de modo que eles são financiados, fundamentalmente, por meio de impostos. Isso implica um elevado grau de solidariedade entre todos os membros da sociedade. Esse modelo é caracterizado por um grau intermediário de regulamentação do mercado de trabalho, mas também por elevados incentivos à demanda e à oferta de trabalho, o que se converte em uma elevada taxa de emprego, sobretudo entre as mulheres, a quem é assegurada maior capacidade de conciliar a vida familiar e profissional relativamente aos demais modelos. A reduzida parcela da sociedade em situação de vulnerabilidade faz com que poucos precisem recorrer aos mecanismos de assistência pública, que, mesmo assim, são bastante sofisticados. Dessa forma, o modelo escandinavo implica um grau elevado de desmercantilização e desfamiliarização, bem como um grau elevado de coesão social, com níveis reduzidos de miséria e de pobreza, bem como de desigualdades sociais, relativamente aos demais modelos.

Por fim, no modelo mediterrâneo, o Estado possui um papel mais importante que o mercado, mas menos relevante que a família. Os laços de solidariedade não se restringem apenas à família nuclear, mas também à família estendida, compreendendo três, às vezes quatro, gerações. Os benefícios básicos cobrem um conjunto razoável de riscos. Para alguns deles, os benefícios variam em função da ocupação, sendo o acesso dependente do pagamento de contribuições. Para outros riscos, os benefícios são modestos, mas o acesso independe do pagamento de contribuições, de modo que eles são financiados, fundamentalmente, por meio de impostos. Esse modelo é caracterizado por um elevado grau de regulamentação do mercado de trabalho, ainda que apresente uma tendência à flexibilização da legislação trabalhista. Ele também apresenta elevada importância da economia informal, em que se encontram principalmente as mulheres, os jovens e os idosos de menor qualificação, que dessa forma complementam a renda familiar nos casos em que o homem não pode assegurar o atendimento de suas necessidades e de sua família por meio de seu salário e de seus benefícios. A despeito da parcela expressiva da sociedade em situação de vulnerabilidade, os mecanismos de assistência pública ainda são pouco desenvolvidos. É ainda notável a maior incidência de práticas clientelistas, isto é, baseadas em troca de favores entre aqueles que desejam o poder e aqueles de quem esse poder emana. Dessa forma, o modelo mediterrâneo implica um grau médio de desmercantilização e um grau reduzido de desfamiliarização, mas também um baixo grau de coesão social, com elevados níveis de miséria e de pobreza, bem como de desigualdades sociais, relativamente aos demais modelos da Europa Ocidental. 
Em suma, esses diferentes arranjos permitem afirmar que o grau de sofisticação dos Estados de Bem-Estar Social não é uma consequência inequívoca do grau de desenvolvimento das forças produtivas capitalistas em determinada sociedade. Evidentemente, esse é um aspecto relevante, na medida em que pode assegurar os recursos necessários para financiar a proteção dos indivíduos contra os riscos a que eles estão sujeitos ao longo da vida. Entretanto, isso não garante a existência de Estados de Bem-Estar Social sofisticados. Prova disso é que sociedades que apresentam graus semelhantes de desenvolvimento das forças produtivas possuem sistemas de proteção social muito diferentes entre si, o que, por seu turno, reflete-se nas diferenças existentes em termos de condições de vida prevalecentes em cada uma delas (Wilensky, 1975; Quadagno, 1987).

É evidente, nesse sentido, que os modelos de Estados de Bem-Estar Social apresentam diferentes graus de sofisticação de acordo com a amplitude dos direitos sociais em cada um deles, tanto no que se refere ao seu conteúdo como no que diz respeito à parcela da sociedade que deles são investidos. São, pois, essas duas dimensões que determinam a capacidade desses arranjos de afetar as condições de vida prevalecentes em determinadas sociedades. $O$ processo de ampliação progressiva da cidadania, manifestado na ampliação desses direitos, faz com que a igualdade formal e abstrata pressione no sentido da igualdade real e concreta, ao menos até que as diferenças existentes entre os indivíduos, no que se refere às suas condições de vida, não ofendam a concepção prevalecente em cada sociedade do que é ou não tolerável (Marshall, 1950, p. 36).

\subsection{Evidências}

A seguir, analisa-se um conjunto de dados e indicadores selecionados para os diferentes modelos de Estado de Bem-Estar Social da Europa Ocidental nas três décadas que antecederam a deflagração da crise global em $2008^{10}$, de sorte a capturar as diferenças existentes entre eles e as consequências dessas diferenças em termos das condições de vida prevalecentes em cada um deles. Para cada um desses modelos, então, são apresentadas as médias aritméticas dos valores disponíveis para os períodos de 1980 a 1989, de 1990 a 1999 e de 2000 a 2007. Os valores de cada modelo, por sua vez, são obtidos pelo cálculo das médias aritméticas dos valores obtidos para cada um dos países que os compõem, isto é, Irlanda e Reino Unido, no caso dos países anglo-saxões; Alemanha, Áustria, Bélgica, França e Países Baixos, dos países continentais; Dinamarca, Finlândia e Suécia, dos países escandinavos; e Espanha, Grécia, Itália e Portugal, dos países mediterrâneos ${ }^{11}$.

(10) Sobre a crise global, ver, por exemplo, Torres Filho (2009) e Belluzzo (2012).

(11) Para os valores de cada país individualmente, ver Wolf (2015). 
Como mostra a Tabela 1, as diferenças entre os modelos de Estado de BemEstar Social da Europa Ocidental explicitam-se, desde logo, na magnitude do gasto social. O crescimento do gasto social público foi maior nos países mediterrâneos ao longo do período considerado, pois foi justamente nesse intervalo que eles implementaram um conjunto de reformas em seus sistemas de proteção social com o objetivo de desenvolvê-los. Esses países superaram o nível de gasto social público dos países anglo-saxões, mas, ainda assim, permanecem muito atrás dos países continentais e, principalmente, dos países escandinavos. Isso constitui uma evidência, pois, de que o grau de sofisticação dos sistemas de proteção social é maior no caso dos países escandinavos e continentais e menor no caso dos países anglosaxões e mediterrâneos.

Tabela 1

Gasto social (\% do PIB) - 1980-89, 1990-99 e 2000-07 (médias)

\begin{tabular}{l|c|c|c|c|c|c|c|c|c|c|c|c}
\hline & \multicolumn{3}{|c}{ Anglo-Saxão } & \multicolumn{3}{c|}{ Continental } & \multicolumn{3}{c|}{ Escandinavo } & \multicolumn{3}{c}{ Mediterrâneo } \\
\cline { 2 - 13 } & $\begin{array}{c}1980- \\
1989\end{array}$ & $\begin{array}{c}1990- \\
1999\end{array}$ & $\begin{array}{c}2000- \\
2007\end{array}$ & $\begin{array}{c}1980- \\
1989\end{array}$ & $\begin{array}{c}1990- \\
1999\end{array}$ & $\begin{array}{c}2000- \\
2007\end{array}$ & $\begin{array}{c}1980- \\
1989\end{array}$ & $\begin{array}{c}1990- \\
1999\end{array}$ & $\begin{array}{c}2000- \\
2007\end{array}$ & $\begin{array}{c}1980- \\
1989\end{array}$ & $\begin{array}{c}1990- \\
1999\end{array}$ & $\begin{array}{c}2000- \\
2007\end{array}$ \\
\hline Gasto total & 21,0 & 21,8 & 21,3 & 26,3 & 28,7 & 29,2 & 25,3 & 31,0 & 28,8 & 16,1 & 20,5 & 23,1 \\
\hline Gasto público & 18,1 & 17,8 & 17,4 & 23,9 & 25,5 & 25,7 & 24,1 & 29,1 & 26,5 & 15,6 & 19,1 & 21,6 \\
\hline Gasto privado & 2,9 & 4,0 & 3,9 & 2,4 & 3,2 & 3,5 & 1,2 & 1,9 & 2,3 & 0,5 & 1,4 & 1,5 \\
\hline
\end{tabular}

Nota: Os gastos sociais (total, público e privado) não incluem os gastos em educação. Fonte: OCDE. Elaboração própria.

O gasto social privado também apresentou crescimento considerável em todos os países, ainda que ele seja maior no caso dos países anglo-saxões, onde prevalece o entendimento de que os indivíduos são responsáveis pelo atendimento de suas necessidades e de seus dependentes. Em alguns desses países, os estímulos concedidos pelo Estado, por meio do sistema tributário, contribuíram para esse crescimento. Grande parte da redução ou eliminação dos tributos nesses países é oferecida aos empregadores para que estes adquiram proteção para os seus empregados no mercado, sobretudo no que se refere à previdência e à saúde. Nos países anglo-saxões, esses incentivos fiscais são frequentemente superiores a $2 \%$ do PIB, sendo a maior parte deles para a aquisição de planos de aposentadoria privados. Já nos países continentais e mediterrâneos, eles são raramente superiores a 1\%, nesse caso sendo a maior parte deles para a aquisição de planos de saúde privados. Por fim, nos países escandinavos, esses incentivos fiscais são praticamente inexistentes.

A Tabela 2, por sua vez, revela que as diferenças entre esses arranjos se explicitam também na forma de como esse gasto social público é financiado. Nesse 
caso, os impostos prevalecem sobre as contribuições no caso dos países escandinavos e anglo-saxões, ao passo que as contribuições são preponderantes no caso dos países continentais e mediterrâneos. Deve-se observar que o impacto redistributivo dos impostos é maior do que o das contribuições, pois, naquele caso, os recursos são empregados de acordo com a necessidade, ao passo que, neste caso, eles são alocados de acordo com a capacidade de pagamento. Logo, esse impacto redistributivo é maior no caso dos países escandinavos e anglo-saxões e menor no caso dos países continentais e mediterrâneos. Além disso, os impostos são menos onerosos que as contribuições no que se refere à competitividade da economia, uma vez que estas são frequentemente cumulativas, ou seja, incidem sobre o valor total do bem ou serviço em cada etapa da produção, ao invés de somente sobre o valor adicionado. Dessa forma, o impacto dos impostos sobre os custos de produção e, consequentemente, sobre os preços dos bens e serviços produzidos por uma economia é consideravelmente menor.

Tabela 2

Financiamento do gasto social público (\% do total) - 1990-99 e 2000-07 (médias)

\begin{tabular}{l|c|c|c|c|c|c|c|c}
\hline & \multicolumn{2}{|c|}{ Anglo-saxões } & \multicolumn{2}{c|}{ Continental } & \multicolumn{2}{c|}{ Escandinavo } & \multicolumn{2}{c}{ Mediterrâneo } \\
\cline { 2 - 9 } & $\begin{array}{c}1990- \\
1999\end{array}$ & $\begin{array}{c}2000- \\
2007\end{array}$ & $\begin{array}{c}1990- \\
1999\end{array}$ & $\begin{array}{c}2000- \\
2007\end{array}$ & $\begin{array}{c}1990- \\
1999\end{array}$ & $\begin{array}{c}2000- \\
2007\end{array}$ & $\begin{array}{c}1990- \\
1999\end{array}$ & $\begin{array}{c}2000- \\
2007\end{array}$ \\
\hline Contribuições & 44,5 & 43,4 & 68,0 & 65,6 & 37,1 & 43,1 & 62,4 & 57,7 \\
\hline Impostos & 54,7 & 53,9 & 25,7 & 29,8 & 54,8 & 51,4 & 30,7 & 36,4 \\
\hline Outros & 0,7 & 2,7 & 6,3 & 4,6 & 8,0 & 5,5 & 6,9 & 5,8 \\
\hline
\end{tabular}

Nota: Informações indisponíveis ou insuficientes para o período de 1980-89.

Fonte: Eurostat. Elaboração própria.

A Tabela 3 apresenta a proporção do PIB apropriada pelo Estado sob a forma de tributos. Tradicionalmente, a carga de impostos e contribuições é maior no caso dos países escandinavos e continentais e menor no caso dos países anglo-saxões e mediterrâneos. No que se refere aos impostos, aqueles incidentes sobre a renda e a propriedade normalmente prevalecem sobre os que incidem sobre os bens e serviços, o que se mostra positivo do ponto de vista redistributivo, na medida em que eles tendem a ser progressivos, isto é, maiores para aqueles que possuem renda e patrimônio mais elevados. Já no que diz respeito às contribuições, aquelas pagas pelos empregadores tendem a prevalecer sobre as arcadas pelos beneficiários, que incluem os trabalhadores assalariados e os trabalhadores autônomos - condição considerada positiva do ponto de vista social. 
Tabela 3

Impostos e contribuições (\% do PIB) - 1980-89, 1990-99 e 2000-07 (médias)

\begin{tabular}{l|c|c|c|c|c|c|c|c|c|c|c|c}
\hline & \multicolumn{3}{|c|}{ Anglo-Saxão } & \multicolumn{3}{c|}{ Continental } & \multicolumn{3}{c|}{ Escandinavo } & \multicolumn{3}{c}{ Mediterrâneo } \\
\cline { 2 - 16 } & $\begin{array}{c}1980- \\
1989\end{array}$ & $\begin{array}{c}1990- \\
1999\end{array}$ & $\begin{array}{c}2000- \\
2007\end{array}$ & $\begin{array}{c}1980- \\
1989\end{array}$ & $\begin{array}{c}1990- \\
1999\end{array}$ & $\begin{array}{c}2000- \\
2007\end{array}$ & $\begin{array}{c}1980- \\
1989\end{array}$ & $\begin{array}{c}1990- \\
1999\end{array}$ & $\begin{array}{c}2000- \\
2007\end{array}$ & $\begin{array}{c}1980- \\
1989\end{array}$ & $\begin{array}{c}1990- \\
1999\end{array}$ & $\begin{array}{c}2000- \\
2007\end{array}$ \\
\hline Impostos & 28,8 & 27,4 & 26,6 & 25,2 & 25,3 & 25,5 & 35,9 & 37,2 & 37,0 & 17,6 & 22,0 & 23,4 \\
\hline $\begin{array}{l}\text { Renda e } \\
\text { Propriedade }\end{array}$ & 15,6 & 15,0 & 15,7 & 13,0 & 13,1 & 13,4 & 21,8 & 22,8 & 22,6 & 8,0 & 10,9 & 11,7 \\
\hline $\begin{array}{l}\text { Bens e } \\
\text { Serviços }\end{array}$ & 12,7 & 11,9 & 10,8 & 11,1 & 11,1 & 10,9 & 13,5 & 13,8 & 13,6 & 9,4 & 11,0 & 11,1 \\
\hline Outros & 0,5 & 0,4 & 0,1 & 1,0 & 1,1 & 1,1 & 0,6 & 0,6 & 0,8 & 0,3 & 0,2 & 0,7 \\
\hline Contribuições & 5,5 & 5,0 & 5,0 & 14,7 & 15,1 & 14,0 & 7,3 & 8,9 & 8,4 & 9,2 & 10,0 & 10,6 \\
\hline Empregadores & 3,2 & 3,0 & 3,1 & 7,9 & 7,3 & 7,3 & 6,3 & 6,9 & 6,1 & 6,0 & 6,3 & 6,6 \\
\hline Beneficiários & 2,3 & 2,0 & 1,9 & 6,9 & 7,8 & 6,7 & 1,0 & 2,0 & 2,3 & 3,0 & 3,8 & 4,0 \\
\hline
\end{tabular}

Fonte: OCDE. Elaboração própria.

Uma vez que na avaliação dos diferentes modelos de Estado de Bem-Estar Social não importa apenas quanto dinheiro é gasto, mas também como ele é gasto, deve-se considerar também a composição do gasto social público. E aqui é fundamental observar a importância do gasto relacionado aos mecanismos de assistência pública, ou seja, que dependem da comprovação de necessidade via teste de meios e que são financiados via impostos. Esses benefícios funcionam como um socorro de última instância, destinado a aliviar a privação normalmente associada às situações de miséria e de pobreza, ao assegurar um mínimo abaixo do qual ninguém deverá estar, ou seja, uma "rede de proteção". Além disso, esses benefícios são tradicionalmente fonte de vergonha e de estigma e, consequentemente, de segregação social. Nesse caso, eles nem sempre são capazes de assegurar a integração ou reintegração dos beneficiários na vida social. Como pode ser verificado na Tabela 4, esses benefícios são tradicionalmente mais importantes no caso dos países anglo-saxões, mas a sua importância aumentou também nos países continentais e mediterrâneos no período considerado.

Tabela 4

Benefícios sujeitos a teste de meios (\% do total) - 1990-99 e 2000-07 (médias)

\begin{tabular}{c|c|c|c|c|c|c|c|c}
\hline & \multicolumn{2}{|c|}{ Anglo-Saxão } & \multicolumn{2}{c|}{ Continental } & \multicolumn{2}{c|}{ Escandinavo } & \multicolumn{2}{c}{ Mediterrâneo } \\
\cline { 2 - 9 } & $1990-$ & $2000-$ & $1990-$ & $2000-$ & $1990-$ & $2000-$ & $1990-$ & $2000-$ \\
1999 & 2007 & 1999 & 2007 & 1999 & 2007 & 1999 & 2007 \\
\hline Teste de meios & 24,2 & 20,1 & 8,0 & 9,2 & 7,0 & 4,0 & 8,8 & 9,1 \\
\hline
\end{tabular}

Fonte: Eurostat. Elaboração própria.

Interessante notar, ainda, que o crescimento dos mecanismos de assistência pública nos países continentais e mediterrâneos para fazer frente à parcela da sociedade em situação de vulnerabilidade reflete uma mudança no perfil de atuação do Estado, uma vez que, tradicionalmente, essa era uma responsabilidade dos 
mecanismos de assistência privada, normalmente organizada por instituições filantrópicas e, portanto, sem fins lucrativos, frequentemente de natureza religiosa. Essas instituições são financiadas principalmente por meio de doações por parte do setor privado. Entretanto, elas também contam com o incentivo do setor público, seja pelo financiamento direto, seja por meio de incentivos fiscais.

Em geral, esses benefícios podem ser oferecidos em dinheiro ou em espécie, sendo normalmente restritos a um determinado período e sujeitos a condicionalidades. Mais recentemente, em quase todos os países da Europa Ocidental, ganharam importância, no âmbito dos benefícios sujeitos a tese de meios, aqueles mecanismos destinados a assegurar um rendimento mínimo aos indivíduos e suas famílias. Dentre esses mecanismos, destacam-se os complementos de renda e, cada vez mais, também os "créditos tributários", os quais surgem não apenas nos países anglo-saxões, mas também nos países continentais, mediterrâneos e escandinavos. Frequentemente, esses benefícios possuem, como principal condicionalidade, que os beneficiários estejam trabalhando ou à procura de emprego e dispostos a aceitar a primeira oportunidade que lhes for oferecida ${ }^{12}$.

A Tabela 5 apresenta o gasto social público segundo a sua função, ou seja, de âmbitos selecionados nos quais o Estado frequentemente intervém de alguma forma tendo em vista a provisão do bem-estar social. Incluiu-se aqui, então, os benefícios relacionados à idade, à incapacidade (invalidez, acidente e doença), ao desemprego, à família, ao mercado de trabalho e à saúde.

No que se refere à previdência, vale dizer, à proteção diante da impossibilidade de se obter um rendimento, de forma temporária ou permanente, em função de idade, incapacidade ou desemprego, ela ainda responde pela maior parte do gasto social público em todos os países da Europa Ocidental. Mas esses países diferem em relação à forma desses arranjos. Nos países continentais e nos países mediterrâneos, os benefícios variam de acordo com os rendimentos e a participação é compulsória. $\mathrm{O}$ arranjo varia de acordo com a ocupação, sendo que alguns asseguram benefícios elevados, com alta recomposição dos rendimentos perdidos, e outros asseguram benefícios reduzidos, com baixa recomposição, sendo que essas diferenças tendem a ser mais pronunciadas no caso dos países mediterrâneos que no caso dos países continentais. Já nos países anglo-saxões e escandinavos é possível

(12) A lógica subjacente a esses mecanismos é bastante simples. Em geral, os indivíduos podem obter um nível mínimo de renda sem pagar qualquer imposto sobre ela. Esse limite de isenção tributária depende de um conjunto de critérios, como o tamanho da família e a idade de seus membros. Se a renda é superior a esse limite, paga-se o imposto sobre a parcela excedente de acordo com a alíquota definida para cada faixa de renda. Já se a renda é inferior a esse limite, simplesmente não há qualquer imposto a ser pago. Com o crédito tributário, os indivíduos cuja renda é inferior ao limite de isenção possuem direito a receber uma transferência em dinheiro do Estado. O valor da transferência seria equivalente a uma fração da diferença entre a renda do indivíduo e o limite da isenção. À medida que essa diferença diminui, reduz-se o valor da transferência, mas aumenta-se o valor da renda total recebida pelo indivíduo. 
identificar um arranjo no qual os benefícios básicos são constantes e outro no qual os benefícios complementares variam de acordo com o rendimento. Em ambos os casos, a participação no caso do arranjo básico é compulsória, enquanto que a participação no sistema complementar é voluntária nos países anglo-saxões e compulsória nos países escandinavos. Os benefícios tendem a ser modestos nos países anglo-saxões, assegurando baixa recomposição dos rendimentos perdidos, e elevada nos países escandinavos, assegurando elevada recomposição. Esses benefícios são financiados por contribuições, nos países continentais e mediterrâneos, mas também anglo-saxões. No caso dos países escandinavos, apenas o arranjo complementar é financiado por contribuições, sendo que o arranjo básico é financiado por impostos ${ }^{13}$.

Tabela 5

Composição do gasto social público (\% do PIB) - 1980-89, 1990-99 e 2000-07 (médias)

\begin{tabular}{|c|c|c|c|c|c|c|c|c|c|c|c|c|}
\hline & \multicolumn{3}{|c|}{ Anglo-Saxão } & \multicolumn{3}{|c|}{ Continental } & \multicolumn{3}{|c|}{ Escandinavo } & \multicolumn{3}{|c|}{ Mediterrâneo } \\
\hline & $\begin{array}{c}1980- \\
1989\end{array}$ & $\begin{array}{c}1990- \\
1999\end{array}$ & $\begin{array}{l}2000- \\
2007\end{array}$ & $\begin{array}{c}1980- \\
1989\end{array}$ & $\begin{array}{c}1990- \\
1999\end{array}$ & \begin{tabular}{|c|}
$2000-$ \\
2007
\end{tabular} & $\begin{array}{c}1980- \\
1989\end{array}$ & $\begin{array}{c}1990- \\
1999\end{array}$ & $\begin{array}{l}2000- \\
2007\end{array}$ & $\begin{array}{c}1980- \\
1989\end{array}$ & $\begin{array}{c}1990- \\
1999\end{array}$ & $\begin{array}{c}2000- \\
2007\end{array}$ \\
\hline Idade & 4,4 & 4,5 & 4,2 & 8,2 & 8,1 & 8,6 & 7,1 & 8,6 & 8,2 & 6,0 & 8,4 & 9,2 \\
\hline Incapacidade & 1,9 & 2,1 & 2,0 & 3,4 & 3,0 & 2,5 & 4,0 & 4,4 & 4,5 & 2,1 & 1,9 & 1,8 \\
\hline Desemprego & 2,3 & 1,5 & 0,6 & 1,9 & 2,0 & 1,7 & 2,1 & 3,1 & 2,0 & 1,0 & 1,2 & 0,9 \\
\hline Merc. de trabalho & 0,9 & 0,8 & 0,5 & 0,8 & 1,0 & 1,0 & 1,1 & 1,7 & 1,3 & 0,2 & 0,4 & 0,5 \\
\hline Família & 1,8 & 2,2 & 2,8 & 2,4 & 2,3 & 2,4 & 3,1 & 3,8 & 3,3 & 0,6 & 0,7 & 1,2 \\
\hline Saúde & 5,3 & 5,1 & 5,9 & 5,7 & 6,8 & 7,3 & 6,9 & 6,7 & 7,1 & 4,2 & 5,0 & 6,0 \\
\hline
\end{tabular}

Fonte: OCDE. Elaboração própria.

Dentre os países da Europa Ocidental, os países escandinavos destacam-se pela ênfase atribuída aos benefícios relacionados à família, os quais são, em geral, financiados por meio de impostos. Mais do que quaisquer outros, esses países se distinguem pelas prestações familiares, pelas licenças parentais e, principalmente, pelos serviços de cuidado profissional de crianças e idosos ${ }^{14}$. Isso reflete o

(13) O financiamento dos sistemas de previdência via contribuições pode se basear no mecanismo de repartição simples ou no mecanismo de capitalização. No primeiro caso, as receitas obtidas pelo pagamento de contribuições são utilizadas para o pagamento das despesas que ocorrem no mesmo período. Já no mecanismo de capitalização, as receitas obtidas pelas contribuições são acumuladas em nome do contribuinte, de modo que elas deverão estar disponíveis a ele quando necessário. Esses recursos são normalmente aplicados no mercado financeiro.

(14) Os serviços de cuidado profissional de crianças em idade pré-escolar têm como principal objetivo assegurar que todas as crianças cheguem à escola nas mesmas condições e que, dessa forma, tenham, efetivamente, as mesmas oportunidades de desenvolvimento, independentemente de sua origem. Isso significa que esses serviços possuem, como principal objetivo, assegurar que o futuro de um cidadão não seja determinado, em última instância, pelas facilidades ou dificuldades decorrentes das condições de vida de sua família, ou, o que é equivalente, pela sua "herança social". Já os serviços de cuidado profissional de idosos têm como principal objetivo assegurar a possibilidade de que os indivíduos em idade avançada possam viver de forma independente. Eles buscam assegurar que eles permaneçam em casa pelo maior tempo possível, o que permite a proximidade junto à sua família e ao resto da sociedade. Em geral, o cuidado em instituições especializadas restringe-se apenas àqueles que exigem cuidados sofisticados (Esping-Andersen; Palier, 2009). 
entendimento prevalecente nesses países de que a família não deve arcar sozinha com a responsabilidade pelo atendimento das necessidades fundamentais de seus membros. Isso porque, muitas vezes, por forças além de seu controle, ela pode não ser capaz de fazer isso de forma adequada. Por essa razão, essa tarefa deve ser compartilhada com toda a sociedade, por meio da ação do Estado (Orloff, 1996; Sainsbury, 2000; Draibe, 2006).

De fato, esses benefícios contribuem para a redução dos custos associados à formação de uma família e permitem aos indivíduos conciliar a vida familiar e a vida profissional com maior facilidade. Isso constitui um estímulo importante ao aumento da taxa de fertilidade, isto é, do número médio de filhos por mulher, nesses países. Isso porque uma taxa de fertilidade reduzida não reflete, necessariamente, que os indivíduos desejam ter menos filhos, mas que as condições para tanto são mais restritivas do que costumavam ser no passado. De fato, os países em que esses benefícios são desenvolvidos são também os que possuem as maiores taxas de fertilidade da Europa Ocidental: cerca de dois filhos por mulher, frente a um filho por mulher no resto do continente.

Deve-se observar que os benefícios destinados à família sempre enfrentaram grande resistência nos países continentais e, principalmente, nos países mediterrâneos. Isso se deve, em grande medida, ao entendimento prevalecente nesses países de que o Estado não deve intervir na vida familiar. Quando muito, ele deve apenas facilitar o exercício de responsabilidades que são, na verdade, exclusivas de seus membros, o que é coerente com o princípio de que as necessidades fundamentais dos indivíduos devem ser atendidas, primeiramente, por aqueles mais próximos à sua realidade. Nesses países é ainda mais evidente a divisão de tarefas no âmbito familiar, cabendo ao homem o "sustento do lar" e à mulher o "cuidado de seus membros". Nesse caso, para que uma parcela expressiva da população estivesse protegida, seria necessário que todos os homens estivessem protegidos em função da sua ocupação e que as famílias fossem estáveis. Se o homem não for capaz de encontrar uma ocupação e/ou se as famílias forem compostas apenas por mães solteiras ou divorciadas, então uma parcela expressiva da sociedade estará desprotegida (Kerstenetzky, 2012) ${ }^{15}$.

(15) Isso se deve, em grande medida, à forte tradição religiosa nesses países. De particular importância é a doutrina social católica, cujos fundamentos foram estabelecidos pela encíclica Rerum Novarum, escrita pelo Papa Leão XIII e publicada em 1891. A reticência católica em relação à expansão da ação do Estado não é um consenso entre os protestantes. Em geral, essa reticência não é partilhada pelos protestantes de inspiração luterana, mas sim pelos protestantes de outras inspirações, como os calvinistas. Interessante notar, onde o protestantismo de inspiração luterana prevalece, as relações entre o Estado e a Igreja são muito mais estreitas que onde o catolicismo e o protestantismo de outras inspirações prevalecem, evitando o conflito de interesses, inclusive porque, nesses países, a Igreja é uma instituição subordinada ao Estado (Kersbergen; Manow, 2009). 
Os países escandinavos também se destacam pelos benefícios relacionados ao mercado de trabalho, os quais são, em geral, também financiados por meio de impostos. Eles não se restringem às políticas passivas, voltadas para a manutenção dos indivíduos que se encontram fora do mercado de trabalho, mas também compreendem as políticas ativas, voltadas para a inserção ou reinserção desses indivíduos no mercado de trabalho, sendo muitas delas destinadas aos segmentos tradicionalmente excluídos desse mercado, como as mulheres, os jovens e os idosos, por exemplo. Dentre essas políticas ativas, destacam-se os serviços de intermediação entre ofertantes e demandantes de emprego, os quais são realizados por meio de agências públicas; a concessão de subsídios aos demandantes de trabalho, os quais incluem desde incentivos fiscais até o pagamento de parte dos salários pelo Estado; os serviços de qualificação e requalificação; os incentivos para o desenvolvimento de pequenas e médias empresas, bem como para o trabalho autônomo; e a criação de empregos pelo Estado, por meio de obras públicas, por exemplo (Stephens, 1996).

Já no que se refere à saúde, prevalecem nos países europeus dois sistemas públicos: o sistema "beveridgeano" e o sistema "bismarckiano". No primeiro caso, os serviços de diagnóstico, tratamento e reabilitação, são majoritariamente universais e financiados por meio de impostos. Embora os países anglo-saxões tenham sido os primeiros a criar sistemas dessa natureza, é cada vez mais evidente ali o processo de privatização, seja na forma de administração, seja na provisão dos serviços. Os países anglo-saxões foram seguidos pelos países escandinavos e, mais recentemente, também pelos países mediterrâneos. Já no segundo sistema, os serviços não são universais, sendo financiados por meio de contribuições. Esse sistema prevalece no caso dos países continentais ${ }^{16}$ (OECD, 1985; Blank; Burau, 2007; Freeman; Rothgang, 2010; Moran, 2000).

Evidentemente, a capacidade do sistema beveridgeano de assegurar o acesso aos serviços de saúde a uma parcela considerável da sociedade é muito maior do que no caso do sistema bismarckiano, o que permite que as condições de saúde prevalecentes nos países que adotam o primeiro sistema sejam bastante satisfatórias relativamente aos países que adotam o segundo sistema. De qualquer forma, em todos os países europeus, a mortalidade infantil diminuiu consideravelmente, sendo hoje inferior a 5 a cada 1000, contra 10 em 1980, em função do maior cuidado assegurado às mães e aos filhos desde o início da gestação. Houve, ainda, um

(16) Em geral, a proporção da sociedade que possui planos de saúde privados é maior nos países em que prevalece o sistema bismarckiano do que nos países em que prevalece o sistema beveridgeano. Entretanto, a natureza desses planos varia nos dois grupos. No primeiro caso, prevalecem os planos de saúde privados para cobrir despesas não cobertas pelo sistema público ou cobertas apenas parcialmente por ele. Já no segundo caso, prevalecem os planos para cobrir despesas que são cobertas pelo sistema público, mas de modo insatisfatório, sobretudo no que se refere à liberdade de escolha do provedor de serviços (médicos, hospitais etc.), ao tempo de espera para o acesso a determinados serviços (exames, cirurgias etc.) e à qualidade dos serviços prestados (hospedagem etc.), entre outros. 
aumento considerável da expectativa de vida, sendo atualmente superior a 80 anos, contra 75 anos em 1980, em função da redução das mortes causadas por fatores tradicionais, como doenças transmissíveis. De fato, esses sistemas procuram hoje incorporar os avanços na área da saúde para enfrentar as ameaças associadas aos hábitos e modos de vida prevalecentes nas sociedades contemporâneas.

Esse aumento da expectativa de vida, por sua vez, contribui consideravelmente para o aumento da taxa de dependência, isto é, da importância da população mais velha relativamente à população mais jovem na sociedade. De fato, essa proporção é hoje de quase $25 \%$, contra $20 \%$ em 1980 , ainda que ela seja menor nos países que apresentam maiores taxas de fertilidade, como é o caso dos países anglo-saxões e escandinavos, e menor onde essas taxas são menores, como ocorre nos países continentais e mediterrâneos. Em qualquer um dos casos, entretanto, a situação não é confortável, uma vez que o envelhecimento da população pressupõe um aumento nas despesas sem um aumento equivalente das receitas do sistema de proteção social, sobretudo em função da maior demanda por benefícios nos âmbitos da previdência e da saúde. Assim sendo, a principal forma de se viabilizar a sustentabilidade financeira desses sistemas de proteção ao longo do tempo é assegurar que mais pessoas estejam produzindo mais riqueza.

Nesse contexto, a Tabela 6 mostra o comportamento da taxa de desemprego e da taxa de emprego para os quatro modelos de Estado de Bem-Estar Social da Europa Ocidental. Os países escandinavos se destacam não apenas por apresentar taxas de desemprego reduzidas, mas também e, principalmente, por apresentar taxas de emprego elevadas, o que está intimamente relacionado ao maior grau de desenvolvimento das políticas de estimulo ao ingresso no mercado de trabalho, inclusive dos segmentos tradicionalmente excluídos, como as mulheres, os jovens e os idosos. Esses empregos são gerados não apenas pelo setor privado, mas também pelo setor público, que, evidentemente, é bastante importante em função do grau de sofisticação de seus sistemas de proteção social. Em geral, uma maior taxa de emprego, mais do que uma menor taxa de desemprego, significa que mais pessoas estão contribuindo para a produção de riqueza e, consequentemente, de recursos para financiar esses arranjos.

Como sugere a Tabela 7, nem mesmo os países escandinavos permaneceram imunes à tendência ao aumento dos empregos atípicos, isto é, dos empregos em tempo parcial e dos empregos temporários, ainda que essa tendência tenha sido mais forte nos países continentais e mediterrâneos, que avançaram consideravelmente nas reformas de suas legislações trabalhistas, aproximando-as consideravelmente daquelas existentes nos países anglo-saxões, em que a intervenção do Estado no funcionamento do mercado de trabalho é tradicionalmente muito reduzida. Esses países avançaram nesse processo depois de uma tentativa de enfrentar o desemprego 
retirando os indivíduos excedentes no mercado de trabalho, via flexibilização das normas para aposentadorias e pensões. Como não poderia deixar de ser, essa estratégia levou a um aumento considerável do gasto público em previdência, o qual se procurou compensar pelo aumento das contribuições. Entretanto, uma vez que esse processo não poderia continuar indefinidamente, ele foi abandonado na maioria desses países no início da década de 1990 (Esping-Andersen, 1990, 1996b, 1999; Palier; Martin, 2008; Palier, 2010).

Mais recentemente, verifica-se nesses países uma tentativa de conciliar flexibilidade e seguridade, o que deu origem ao modelo de "flexiguridade". Ele surgiu na Dinamarca e pressupõe dois movimentos coordenados. Primeiro, na redução da regulamentação do mercado de trabalho e, segundo, na sofisticação do sistema de proteção social. Dessa forma, a insegurança decorrente do primeiro movimento seria mais do que compensada pela segurança proporcionada pelo segundo. Esse modelo reflete o entendimento de que a prioridade da ação do Estado no que se refere ao mercado de trabalho deve ser a garantia de um bom emprego, mesmo que não necessariamente do mesmo emprego ao longo de toda a vida, para todos aqueles capazes e dispostos a trabalhar. Nesse caso, portanto, a noção de employment security prevalece sobre a noção de job security ${ }^{17}$ (Madsen, 2004; Viebrock; Clase, 2009).

Tabela 6

Taxa de desemprego (\%) e taxa de emprego (\%) - 1990-99 e 2000-07 (médias)

\begin{tabular}{|c|c|c|c|c|c|c|c|c|}
\hline & \multicolumn{2}{|c|}{ Anglo-Saxão } & \multicolumn{2}{|c|}{ Continental } & \multicolumn{2}{|c|}{ Escandinavo } & \multicolumn{2}{|c|}{ Mediterrâneo } \\
\hline & $\begin{array}{c}1990- \\
1999 \\
\end{array}$ & $\begin{array}{c}2000- \\
2007\end{array}$ & $\begin{array}{c}1990- \\
1999\end{array}$ & $\begin{array}{c}2000- \\
2007\end{array}$ & $\begin{array}{c}1990- \\
1999\end{array}$ & $\begin{array}{c}2000- \\
2007\end{array}$ & $\begin{array}{c}1990- \\
1999\end{array}$ & $\begin{array}{l}2000- \\
2007\end{array}$ \\
\hline \multicolumn{9}{|l|}{ Desemprego } \\
\hline Desemprego (total) & 10,0 & 4,8 & 7,2 & 6,7 & 8,7 & 6,6 & 11,6 & 8,9 \\
\hline Taxa de desemprego ( $<25$ anos $)$ & 16,6 & 10,5 & 15,1 & 14,0 & 16,8 & 15,3 & 27,2 & 22,0 \\
\hline Taxa de desemprego (mulheres) & 9,5 & 4,3 & 8,6 & 7,2 & 8,5 & 6,8 & 16,0 & 11,9 \\
\hline \multicolumn{9}{|l|}{ Emprego } \\
\hline Taxa de emprego (15 a 64 anos) & 62,5 & 69,1 & 63,2 & 66,6 & 69,4 & 72,6 & 55,2 & 61,1 \\
\hline Taxa de emprego (15 a 24 anos) & 48,1 & 52,1 & 43,3 & 44,7 & 45,1 & 48,6 & 30,7 & 31,5 \\
\hline Taxa de emprego (55 a 64 anos) & 44,0 & 52,3 & 29,8 & 36,7 & 50,3 & 59,0 & 37,6 & 40,7 \\
\hline Taxa de emprego (mulheres) & 53,6 & 61,1 & 54,2 & 59,6 & 66,4 & 69,8 & 41,6 & 49,5 \\
\hline
\end{tabular}

Nota: Dados indisponíveis ou insuficientes para os períodos de 1980-89.

Fonte: Eurostat. Elaboração própria.

(17) O modelo dinamarquês chamou a atenção de outros países europeus. De particular importância, foi o caso da Holanda. Nesse caso, entretanto, avançou-se mais na flexibilidade e menos na seguridade, o que levou ao enfraquecimento de um dos mais sofisticados sistemas de proteção social da Europa Ocidental. 
Os Estados de Bem-Estar Social da Europa Ocidental: tipologias, evidências e vulnerabilidades

Tabela 7

Emprego em tempo parcial (\% do total) e temporário (\% do total) - 1990-99 e 2000-07 (médias)

\begin{tabular}{c|c|c|c|c|c|c|c|c}
\hline & \multicolumn{2}{|c|}{ Anglo-Saxão } & \multicolumn{2}{c|}{ Continental } & \multicolumn{2}{c|}{ Escandinavo } & \multicolumn{2}{c}{ Mediterrâneo } \\
\cline { 2 - 10 } & $\begin{array}{c}1990- \\
1999\end{array}$ & $\begin{array}{c}2000- \\
2009\end{array}$ & $\begin{array}{c}1990- \\
1999\end{array}$ & $\begin{array}{c}2000- \\
2009\end{array}$ & $\begin{array}{c}1990- \\
1999\end{array}$ & $\begin{array}{c}2000- \\
2009\end{array}$ & $\begin{array}{c}1990- \\
1999\end{array}$ & $2000-$ \\
2009 \\
\hline Emprego temporário & 7,7 & 5,8 & 9,8 & 11,9 & 14,3 & 13,8 & 16,4 & 19,0 \\
\hline Emprego temporário (mulheres) & 9,4 & 6,7 & 11,5 & 13,2 & 16,0 & 16,1 & 18,1 & 21,2 \\
\hline Emprego tempo parcial & 18,3 & 21,1 & 19,8 & 24,9 & 17,9 & 19,3 & 6,9 & 9,1 \\
\hline Emprego tempo parcial (mulheres) & 34,1 & 37,2 & 38,0 & 44,4 & 28,6 & 29,2 & 12,9 & 16,4 \\
\hline
\end{tabular}

Fonte: Eurostat. Elaboração própria.

Deve-se registrar que nos países mediterrâneos, mais do que nos demais países europeus em que a família surge como um importante mecanismo de provisão, nem todos os homens são capazes de assegurar rendimentos elevados e estáveis, bem como benefícios sociais adequados, capazes de atender as necessidades de toda a família. Nesse caso, mulheres, jovens e idosos normalmente ingressam no mercado de trabalho em condições muito precárias, sobretudo na economia informal. Por essa razão, frequentemente aqueles que podem escolher optam por deixar seus países em busca de melhores condições de emprego no exterior, sobretudo nos países dos modelos continental e escandinavo, mas também do modelo anglo-saxão. Muitas vezes, o envio de recursos pelos familiares no exterior constitui uma fonte de rendimento importante para aqueles que permaneceram no país (Ferrera, 1996; Moreno, 2006; Rhodes, 1997).

Importante notar que as políticas públicas dos países escandinavos possuem forte viés produtivista. Mais do que em quaisquer outros países, essas políticas contribuem para o aumento do número de indivíduos empregados e para a elevação da capacidade produtiva desses indivíduos. Tal como enfatizou Myrdal (1973), não importa apenas a quantidade de mão de obra empregada, mas também a sua qualidade, uma vez que isso asseguraria os meios para o crescimento econômico sustentado. $\mathrm{O}$ bem-estar social passa a ser entendido, assim, como um investimento que não pode ser subordinado à lógica de funcionamento dos mercados. Ademais, ele mostrou que a política produtiva é também, por natureza, preventiva, na medida em que ela é capaz de evitar infortúnios ainda mais graves no futuro ${ }^{18}$ (Anderssen, 2006, Esping-Andersen, 1992).

Consequência inevitável dessa concepção, os países escandinavos destacamse também no que se refere ao comportamento do produto e da renda. Como mostra a Tabela 8, as taxas de crescimento do PIB, bem como os níveis de renda per capita desses países estão entre os maiores da Europa Ocidental ao longo das últimas duas

(18) Gunnar Myrdal era o principal expoente da Escola de Estocolmo, que estabeleceu as bases teóricas para o desenvolvimento do sistema de proteção social sueco após a Grande Depressão da década de 1930. 
décadas. No que diz respeito a essas variáveis, o desempenho desses países é comparável apenas ao das maiores economias da região.

Tabela 8

Crescimento do PIB (\%) e PIB per capita (US\$) - 1980-89, 1990-99 e 2000-07 (médias)

\begin{tabular}{l|c|c|c|c|c|c|c|c|c|c|c|c}
\hline & \multicolumn{3}{|c|}{ Anglo-Saxão } & \multicolumn{3}{c|}{ Continental } & \multicolumn{3}{c}{ Escandinavo } & \multicolumn{3}{c}{ Mediterrâneo } \\
\hline & $1980-$ & $1990-$ & $2000-$ & $1980-$ & $1990-$ & $2000-$ & $1980-$ & $1990-$ & $2000-$ & $1980-$ & $1990-$ & $2000-$ \\
& 1989 & 1999 & 2007 & 1989 & 1999 & 2007 & 1989 & 1999 & 2007 & 1989 & 1999 & 2007 \\
\hline PIB & 3,1 & 4,6 & 4,3 & 2,1 & 2,5 & 2,1 & 2,6 & 2,0 & 2,9 & 2,3 & 2,3 & 2,7 \\
\hline $\begin{array}{l}\text { PIB per } \\
\text { capita }\end{array}$ & 18.124 & 25.107 & 35.968 & 22.892 & 28.095 & 33.161 & 22.356 & 25.916 & 32.636 & 16.982 & 21.125 & 25.747 \\
\hline
\end{tabular}

Fonte: OCDE. Elaboração própria.

Deve-se observar que embora o comportamento do PIB e da renda per capita sejam indicadores do comportamento da riqueza de uma sociedade, eles não revelam como essa riqueza é distribuída entre os seus membros, o que é, evidentemente, determinante para as condições de vida prevalecentes. Nesse caso, é conveniente considerar também o comportamento do chamado "índice de Gini", o qual avalia o grau de concentração da renda em um país e varia de zero, isto é, a igualdade máxima, ou renda totalmente distribuída, e um, ou seja, a desigualdade máxima ou renda totalmente concentrada. Na Tabela 9, o Índice de Gini é apresentado considerando-se, primeiro, a distribuição da renda ou a renda primária - antes de tributos e transferências -, e, depois, a redistribuição da renda ou renda efetivamente disponível - após tributos e transferências.

Tabela 9

Índice de Gini - 2000-07 (médias)

\begin{tabular}{l|c|c|c|c}
\hline & Anglo-Saxão & Continental & Escandinavo & Mediterrâneo \\
\cline { 2 - 5 } & $\begin{array}{c}2000- \\
2007\end{array}$ & $\begin{array}{c}2000- \\
2007\end{array}$ & $\begin{array}{c}2000- \\
2007\end{array}$ & $\begin{array}{c}2000- \\
2007\end{array}$ \\
\hline Antes de tributos e transferências & 0,50 & 0,47 & 0,44 & 0,49 \\
\hline Depois de tributos e transferências & 0,32 & 0,28 & 0,24 & 0,34 \\
\hline
\end{tabular}

Nota: Dados indisponíveis ou insuficientes para os períodos de 1980-89 e 1990-99.

Fonte: OCDE. Elaboração própria.

É particularmente notável o fato de que os países escandinavos possuem o menor grau de concentração da renda mesmo antes de incorporados os efeitos dos tributos e transferências. Isso está relacionado, mais uma vez, às características do mercado de trabalho nesses países. De fato, não apenas mais indivíduos estão empregados nesses países, como mais pessoas recebem salários mais elevados. Além disso, as disparidades entre os salários de trabalhadores de uma mesma ocupação e entre salários de trabalhadores de ocupações diferentes são menores nesses países. Isso se deve, por exemplo, ao processo de negociação entre os representantes dos 
empregados e dos empregadores nesses países, o qual é centralizado e frequentemente intermediado pelo Estado ${ }^{19}$.

Considerando a redistribuição da renda, os países escandinavos também apresentam um desempenho superior, relativamente aos demais países europeus. De um lado, a carga tributária nesses países é mais alta, sendo de particular importância os impostos que incidem sobre a renda e a propriedade, normalmente de caráter progressivo. De outro, as transferências são mais elevadas e beneficiam uma parcela expressiva da sociedade, sendo alocadas frequentemente segundo a necessidade, e não segundo a capacidade de pagamento.

Deve-se enfatizar que a distribuição da renda não é a única medida das desigualdades existentes em uma sociedade. A garantia ou não do acesso a um conjunto de bens e serviços essenciais de elevada qualidade e, mesmo assim, gratuitos ou altamente subsidiados pelo Estado também é um importante fator de redução ou aumento das diferenças entre os indivíduos no que se refere às suas condições de vida e que não são considerados na análise da distribuição da renda primária ou da renda disponível. Como visto, também nesse caso, os países escandinavos estão à frente dos demais países europeus, pertencentes aos outros três modelos analisados.

Cabe ainda observar de que forma as diferenças existentes entre os Estados de Bem-Estar Social dos países da Europa Ocidental se refletem no comportamento dos níveis de miséria e de pobreza prevalecentes nesses países. Nesse sentido, a Tabela 10 apresenta a proporção de pessoas que se encontra abaixo da linha da pobreza, considerada aqui como sendo equivalente a $50 \%$ da renda mediana. Mais uma vez, é considerada a renda antes e depois dos tributos e transferências.

Tabela 10

Taxa de pobreza $(\%)$ - 2000-07 (médias)

\begin{tabular}{c|c|c|c|c}
\hline & Anglo-Saxão & Continental & Escandinavo & Mediterrâneo \\
\cline { 2 - 5 } & $2000-2007$ & $2000-2007$ & $2000-2007$ & $2000-2007$ \\
\hline Antes de tributos e transferências & 32,5 & 30,1 & 26,7 & 30,3 \\
\hline Depois de tributos e transferências & 11,2 & 7,9 & 6,0 & 13,0 \\
\hline Menores de 17 anos & 13,3 & 9,5 & 3,8 & 16,8 \\
\hline Maiores de 76 anos & 18,3 & 9,6 & 13,7 & 20,9 \\
\hline
\end{tabular}

Nota: Dados indisponíveis ou insuficientes para os períodos de 1980-89 e 1990-99.

Fonte: OCDE. Elaboração própria.

19 Não por acaso, os países escandinavos possuem tradicionalmente as maiores taxas de sindicalização entre os empregados entre todos os países da Europa Ocidental. Embora a taxa de sindicalização tenha se reduzido em todo continente nos últimos anos, nos países escandinavos ela é superior a 70\% dos empregados, muito acima, portanto, daquela verificada nos países continentais, mediterrâneos e anglo-saxões, onde ela é raramente superior a $30 \%$ do total. 
É mais uma vez notável o fato de que os países escandinavos possuem os menores níveis de miséria e de pobreza entre os países da Europa Ocidental antes mesmo do efeito dos tributos e transferências. Isso está intimamente relacionado, mais uma vez, ao fato de que mais pessoas trabalham e recebem mais por isso. Depois do efeito dos tributos e transferências, eles continuam à frente dos demais países europeus, mas esses países também apresentam reduções bastante expressivas na parcela da população que se encontra em situação de maior vulnerabilidade. Isso porque, a despeito das diferenças existentes entre esses modelos, todos eles possuem algum mecanismo de assistência pública destinada a socorrer aqueles que não têm mais a quê ou a quem recorrer, ainda que esses mecanismos variem consideravelmente no que se refere ao seu grau de sofisticação.

Também nesse aspecto, os países mediterrâneos permanecem atrás dos demais países europeus, a despeito de avanços recentes. Os benefícios sujeitos a teste de meios se restringem a determinados grupos sociais e são, em geral, mais modestos do que aqueles verificados nos demais países europeus. Nos países mediterrâneos, mais do que em qualquer outro modelo, a responsabilidade pela parcela da sociedade que se encontra em situação de maior vulnerabilidade cabe fundamentalmente às formas tradicionais de provisão, a começar pela família, sendo que elas são, na realidade, cada vez menos capazes de arcar com essa responsabilidade sozinhas.

Por fim, deve-se observar que sistemas de proteção social em que o Estado exerce um papel mais contundente no atendimento das necessidades fundamentais individuais não pressupõem, necessariamente, descontrole das contas públicas, tal como mostra a Tabela 11. Embora o gasto social corresponda a aproximadamente metade dos gastos públicos em todos os países da Europa Ocidental, os impactos sobre o orçamento dependem, mais uma vez, não apenas de quanto dinheiro é gasto por esses arranjos, mas também de como ele é gasto e de que resultados ele produz.

Tabela 11

Déficit público e dívida pública (\% do PIB) - 1980-89, 1990-99 e 2000-07 (médias)

\begin{tabular}{l|c|c|c|c|c|c|c|c}
\hline \multirow{2}{*}{} & \multicolumn{2}{|c|}{ Anglo-Saxão } & \multicolumn{2}{c|}{ Continental } & \multicolumn{2}{c|}{ Escandinavo } & \multicolumn{2}{c}{ Mediterrâneo } \\
\cline { 2 - 9 } & $\begin{array}{c}1999- \\
1999\end{array}$ & $\begin{array}{c}2000- \\
2009\end{array}$ & $\begin{array}{c}1999- \\
1999\end{array}$ & $\begin{array}{c}2000- \\
2009\end{array}$ & $\begin{array}{c}1999- \\
1999\end{array}$ & $\begin{array}{c}2000- \\
2009\end{array}$ & $\begin{array}{c}1999- \\
1999\end{array}$ & $\begin{array}{c}2000- \\
2009\end{array}$ \\
\hline Déficit público & 1,4 & 1,2 & 0,7 & 1,3 & $-0,7$ & 3,6 & 0,7 & 0,7 \\
\hline Dívida pública & 60,1 & 34,7 & 71,4 & 66,9 & 60,8 & 44,2 & 78,8 & 78,4 \\
\hline
\end{tabular}

Nota: Dados indisponíveis ou insuficientes para os períodos de 1980-89.

Fonte: FMI. Elaboração própria.

De fato, os países escandinavos e os países anglo-saxões apresentam contas públicas bastante satisfatórias, caracterizadas por baixos déficit e dívida públicos em relação ao PIB. Entretanto, os países escandinavos possuem arranjos muito mais sofisticados que os países anglo-saxões. Isso é possível porque, apesar do maior nível 
de despesa, esses países asseguram as condições para o crescimento das receitas, o que leva a uma redução do déficit e, assim, da dívida pública. Situação diferente ocorre nos países continentais e mediterrâneos, em que as despesas não são acompanhadas por um aumento das receitas, elevando o déficit público e, assim, a dívida pública, os quais estão, não surpreendentemente, entre os mais elevados entre os países da Europa Ocidental, mesmo considerando o período anterior à deflagração da crise internacional em $2008^{20}$.

Conforme se discute a seguir, existem indícios de que as pressões sobre as despesas dos sistemas de proteção social dos países da Europa Ocidental tenderão a crescer ainda mais nos próximos anos. Nesse contexto, esses países poderão reduzir o gasto público, aproximando-se dos países anglo-saxões, ou alterar a composição desse gasto, aproximando-se dos países escandinavos. Em ambos os casos, isso pressupõe uma mudança no perfil das políticas públicas e, consequentemente, na forma de seus sistemas de proteção social, com resultados possivelmente bastante diferentes em termos econômicos e sociais. O fortalecimento das ideias liberais nesses países - também e paradoxalmente - em razão dos efeitos da crise internacional, sugere uma tendência ao modelo dos países anglo-saxões, onde essas ideias tradicionalmente encontraram apoio.

\subsection{Vulnerabilidades}

Os Estados de Bem-Estar Social da Europa Ocidental estão sujeitos a diferentes fontes de pressão. Nesta breve seção, são apenas apresentadas algumas dessas fontes principais.

A primeira delas é, sem dúvida, as crises econômicas, como a crise europeia recente $^{21}$. No âmbito do capitalismo cada vez mais liberalizado e desregulamentado, esses episódios se tornaram não apenas mais frequentes, mas também disruptivos. Ao pressionar esses arranjos, em vista da comumente "socialização de prejuízos privados" e, por conseguinte, deterioração dos indicadores fiscais das economias, as crises acabam por incitar o seu questionamento e, no limite, a sua desestruturação. Nesse contexto, pode-se afirmar que arranjos mais sofisticados no que se refere ao perfil das políticas públicas, em geral, e das políticas econômica e social, em particular, estão mais bem preparados para lidar com esses episódios, tornando-os

(20) Alguns países criaram fundos especiais destinados a financiar eventuais desequilíbrios entre receitas e despesas no sistema de proteção social - os chamados "fundos de reserva". Os recursos desses fundos possuem origens diversas, como impostos e contribuições especiais e operações de privatização do patrimônio público. Em função da sua natureza, esses fundos atuam como investidores de longo-prazo nos mercados financeiros e podem constituir uma fonte relevante de funding para investimentos públicos e privados. Os maiores fundos públicos de reserva da Europa Ocidental estão na Suécia (32\% do PIB), seguidos pela Irlanda (12\% do PIB), pela Espanha (5\% do PIB), por Portugal (4\% do PIB) e pela França (2\% do PIB).

(21) Sobre a crise europeia no período recente, ver Freitas (2011), Arestis e Sawyer (2012), Belluzzo (2013) e Grahl e Teague (2013). 
menos abruptos e profundos. Isso, por sua vez, alivia as pressões sobre eles, tornando-os menos vulneráveis. Não obstante, como esperado, os arranjos menos sofisticados têm sido forte e adversamente afetados pela crise recente.

Além das crises econômicas, esses arranjos estão sujeitos a um conjunto de transformações estruturais, as quais constituem importantes desafios a serem enfrentados por eles, tendo-se em vista a manutenção da sua capacidade de cumprir aquilo a que eles se propõem, a saber, a proteção dos indivíduos contra as circunstâncias que podem limitar a sua capacidade de viver uma vida considerada adequada de acordo com os padrões que prevalecem na sociedade em um determinado momento histórico. Isso porque essas transformações estruturais criam novas formas de insegurança e, consequentemente, novas necessidades individuais fundamentais.

De fato, esses arranjos surgiram em pleno processo de industrialização. Em geral, a expansão da indústria era capaz de absorver as massas de indivíduos que rapidamente deixavam o campo em direção às cidades, assegurando a elas empregos estáveis e com salários minimamente adequados. Salvo em situações excepcionais, as famílias eram compostas por ambos os pais e eram bastante estáveis. A taxa de fecundidade era elevada e a expectativa de vida ao nascer ainda era reduzida. A cooperação entre os diferentes países assegurava que o desenvolvimento de um desses países não mais precisasse se dar à custa dos demais. O estímulo criterioso ao comércio e ao investimento internacional era acompanhado por mercados financeiros ainda bastante fechados e regulamentados e cujo funcionamento era orientado, em grande medida, para a criação das condições adequadas para o desenvolvimento econômico e social doméstico (Esping-Andersen, 1996a, 1999).

Não obstante, esse contexto sofreu consideráveis transformações nas últimas décadas. O processo de globalização dos mercados, caracterizado pela redução ou eliminação dos obstáculos existentes aos fluxos de internacionais de comércio e de investimento ${ }^{22}$, concorreu para pressionar os países no sentido de assegurar espaços atrativos para a valorização da riqueza privada. Ao dispor de uma saída sempre disponível, os proprietários dessa riqueza aumentam consideravelmente o seu poder sobre o Estado e, consequentemente, sobre o perfil de suas políticas. Além disso, o processo de globalização torna as crises econômicas não apenas mais prováveis como também mais abruptas e profundas. Isso significa importantes fontes de pressão sobre esses arranjos, uma vez que a "socialização das perdas privadas" sempre se segue à “privatização dos ganhos” (Mishra, 1999; Kuhnle, 2007; Belluzzo, 1995).

(22) Processo este, frise-se, que não é o resultado de um "movimento natural" das economias capitalistas, mas, sim, o resultado de uma decisão deliberada do Estado que, por meio de atos e omissões, atenuaram ou eliminaram as restrições sobre esses fluxos. 
Esse é o caso também da transformação das estruturas produtiva e ocupacional nacionais. A era do emprego industrial, estável e de salários adequados, parece ter chegado ao fim. De fato, os serviços ocupam cada vez mais o espaço antes ocupado pela indústria nas diferentes economias. Essas atividades possuem diferentes graus de sofisticação, sendo algumas mais capazes do que outras de agregar valor. E, nesse contexto, os melhores empregos, no que se refere à estabilidade e aos salários, restringem-se àqueles que possuem maior qualificação e experiência. Aos demais, resta o desemprego ou os empregos de menores salários e de menor estabilidade (Ferrera; Hemerijck; Rhodes, 2000).

Por fim, esse é o caso da transformação das estruturas demográfica e familiar. De fato, o aumento da expectativa de vida e a redução da taxa de fertilidade levam a um aumento da proporção de idosos relativamente ao dos jovens e, consequentemente, a um envelhecimento das sociedades, o que pressupõe novas fontes de despesas, mas não de receitas para os sistemas de proteção social. Simultaneamente, houve uma mudança na composição e na estabilidade das famílias. Isso se manifesta, por exemplo, no aumento das famílias monoparentais, sobretudo aquelas compostas por mães solteiras ou divorciadas, que assumem a maior parte da responsabilidade pela criação dos filhos (Taylor-Gooby, 2003; Pierson, 2001; Bonoli, 2005).

\section{Conclusão}

$\mathrm{O}$ artigo mostrou a existência de quatro modelos de Estado de Bem-Estar Social da Europa Ocidental, os quais exercem impactos diferenciados sobre as condições de vida prevalecentes nos países da região. As principais diferenças entre esses modelos se referem à magnitude do gasto social público, à sua forma de financiamento, à composição desse gasto e às exigências para acessar os benefícios que os caracterizam. Isso, por sua vez, se reflete em diferenças importantes no que diz respeito aos níveis de desemprego, subemprego e emprego, ao nível de renda, às desigualdades na distribuição dessa renda e aos níveis de miséria e de pobreza existentes em cada um deles.

Os países da Europa Ocidental cujas políticas públicas são caracterizadas por uma política social produtiva e, também por isso, preventiva, bem como por uma maior articulação entre as políticas social e econômica, estão mais bem preparados para assegurar os direitos de cidadania aos indivíduos relativamente aos demais. Nem o mercado, nem a família, isoladamente, são capazes de assegurar a todos os indivíduos esses direitos.

Polanyi (1944) acreditava que seria possível deter o "moinho" que ameaça triturar e destruir os indivíduos e sua substância humana por meio da substituição da lógica baseada no individualismo e na competição, pelos espíritos do coletivismo e 
da solidariedade como norteadores da vida social. Concretamente, isso implica a intervenção da sociedade nos processos impessoais e automáticos que pressionam as condições de vida dos indivíduos. Como se procurou demonstrar, esta parece ser, precisamente, a essência dos Estados de Bem-Estar Social e que hoje se encontra ameaçada.

\section{Bibliografia}

ANDERSSEN, J. Between growth and security: Swedish social democracy from a strong society to a third way. Manchester, UK: Manchester University Press, 2006. ARESTIS, P.; SAWYER, M. Can the Euro survive after the European crisis? In: ARESTIS, P.; SAWYER, M. The Euro crisis. London, UK: Palgrave Macmillan, 2012.

ARTS, W.; GELISSEN, J. Three worlds of welfare capitalism or more? A state-ofthe-art report. Journal of European Social Policy, London, v. 12, n. 2, p. 137-158, May 2002.

BALDWIN, P. The politics of social solidarity: class bases of the European welfare state, 1875-1975. Cambridge, UK: Cambridge University Press, 1990.

BELluZZO, L. G. Prefácio. In: CINTRA, M. A. M.; MARTINS, A. R. A. As transformações no sistema monetário internacional. Brasília: Ipea, 2013. p. 9-18.

BELLUZZO, L. G. O capital e suas metamorfoses. São Paulo, SP: Ed. Unesp, 2012.

BELLUZZO, L. G. Ensaios sobre o capitalismo no século XX. São Paulo, SP: Ed. Unesp, 2004.

BELluZZO, L. G. O declínio de Bretton Woods e a emergência dos mercados globalizados. Economia e Sociedade, Campinas, n. 4, p.11-20, jun. 1995.

BELLUZZO, L. G.; ALMEIDA, J. S. Enriquecimento e produção: Keynes e a dupla natureza do capitalismo. In: LIMA, G.; SICSÚ, J.; PAULA, L. F. Macroeconomia moderna: Keynes e a economia contemporânea. Rio de Janeiro: Campus, 1999.

BLANK, R.; BURAU, V. Comparative health policy. $2^{\text {nd }}$ ed. New York, US: Palgrave MacMillan, 2007.

BOBBIO, N. Ideologia. In: BOBBIO, N. ; MATTEUCCI, N.; PASQUINO, G. (Org.). Dicionário de política. 11. ed. Brasília, DF: Universidade de Brasília, 1998.

BONOLI, Giuliano. Time matters postindustrialization, new social risks, and welfare state adaptation in advanced industrial democracies. Comparative Political Studies, v. 40, n. 5, p. 495-520, May 2007.

CARVALHO, F. C. Keynes and the reform of the capitalist social order. Journal of Post Keynesian Economics, New York, v. 31, n. 2, p. 191-212, 2008. 
DI GIOVANNI, G. Sistemas de proteção social; uma introdução conceitual. In: OLIVEIRA, M. A. (Org). Reforma do estado e políticas de emprego no Brasil. Campinas, SP: Unicamp-IE, 1998.

DI GIOVANNI, G. As estruturas elementares das políticas públicas. Campinas, SP: NEPP-Unicamp, 2009. (Caderno 82).

DI GIOVANNI, G. Abordagens cognitivas. In: DI GIOVANNI, G.; NOGUEIRA, M. A. (Org). Dicionário de políticas públicas. São Paulo, SP: Imprensa Oficial do Estado de São Paulo, 2013.

DRAIBE, S. Estado de Bem-Estar, desenvolvimento econômico e cidadania: algumas lições da literatura contemporânea. In: ENCONTRO NACIONAL DA ANPOCS, 30, Caxambu, 2006.

ESPING-ANDERSEN, G. The three worlds of welfare capitalism. Princeton, US: Princeton University Press, 1990.

ESPING-ANDERSEN, G. The making of social-democratic welfare state. In: MISGELD, K. MOLIN, K.; ÅMARK, K. Creating social-democracy. A century of the social democratic labour party in Swe-den. Pensylvannia, US: The Pensylvannia State University, 1992.

ESPING-ANDERSEN, G. After the golden age? Welfare state dilemmas in a global economy. In: ESPING-ANDERSEN, G. Welfare states in transition. London, UK: Sage Publications, 1996a.

ESPING-ANDERSEN, G. Welfare states without work: the impasse of labour shedding and familialism in continental European social policy. In: ESPINGANDERSEN, G. Welfare states in transition. London, UK: Sage Publications, 1996 b.

ESPING-ANDERSEN, G. Social foundations of postindustrial economies. Oxford, UK: Oxford University Press, 1999.

ESPING-ANDERSEN, G.; PALIER, B. Três lições sobre o estado-providência. Lisboa, PT: Documentos, 2009.

FERRERA, M. The "southern model" of welfare in social Europe. Journal of European Social Policy, London, v. 6, n. 1, p. 17-37, Feb. 1996.

FERRERA, M.; HAMERIJCK, A. RHODES, M. The future of social Europe: recasting work and welfare in the new economy. Oxford, UK: Oxford University Press, 2000.

FLORA, P.; HEIDENHEIMER, A. J. The development of welfare state in Europe and America. New Brunswick, US: Transaction Books, 1981. 
FREEMAN, R.; ROTHGANG, H. Health. In: CASTLES, F. (Ed.). The Oxford handbook of the welfare state. Oxford: Oxford University Press, 2010.

FREITAS, M. C. P. Crise na área do Euro. Boletim de Economia - Fundap, São Paulo, n. 10, p. 21-45, dez. 2011.

GRAHL, J.; TEAGUE, P. Is the European social model fragmenting? New Political Economy, v. 2, n. 3, p. 405-426, 1997.

IKENBERRY, J. History's heavy hand: institutions and politics of the state. New Perspectives on Institutions. College Park: University of Maryland, 1994.

JUDT, T. Pós-guerra: uma história da Europa desde 1945. Rio de Janeiro: Objetiva, 2008.

KERSBERGEN, K.; MANOW, P. Religion and the western welfare state: theoretical context. In: KERSBERGEN, K.; MANOW, P. Religion, class coalitions and welfare states. Cambridge, UK: Cambridge University Press, 2009.

KERSTENETZKY, C. L. O estado do bem-estar social na idade da razão: a reinvenção do estado social no mundo contemporâneo. Rio de Janeiro, RJ: Elsevier, 2012.

KEYNES, J. M. (1926). The end of laissez-faire. In: JOHNSON, E.; MOGGRIDGE, D. (Ed). The collected writings of John Maynard Keynes. Cambridge, UK: Royal Economic Society, 1978. v. IX.

KEYNES, J. M. (1936). A teoria geral do emprego, do juro e da moeda. São Paulo, SP: Atlas, 2007.

KUHNLE, S. Globalização e o desenvolvimento das políticas sociais. In: DELGADO, M. G.; PORTO, L. V. (Org.). O estado de bem-estar social no século XXI. São Paulo, SP: LTr, 2007.

MADSEN, K. Flexicurity: a new perspective on labour markets and welfare states in Europe. Journal of International and Comparative Law, Cambridge, v. 14, n. 1, 2007.

MARSHALL, T. H. Citizenship and social class and other essays. Cambridge, UK: Cambridge University Press, 1950.

MISHRA, R. Globalization and the welfare state. Cheltenham, UK: Edward Elgar, 1999.

MORAN, M. Understanding the welfare state: the case of health care. British Journal of Politics and International Relations, v. 2, n. 2, p. 135-160, Jun. 2000.

MORENO, L. The model of social protection in southern Europe: enduring characteristics. Jakarta, Indonésia: CSIS, 2006. (Working Papers, n. 6). 
MYRDAL, G. Equity and growth. World Development, New York, v. 1, n. 11, Nov. 1973.

OECD. Financing and delivering health care: a comparative analysis of OECD countries. Social Policy Studies, Paris, n. 4, 1985.

ORLOFF, A. Gender in the welfare state. Annual Review of Sociology, El Camino Way, v. 22, p. 51-78, 1996.

PALIER, B. Ordering change: understanding the 'Bismarckian' welfare reform trajectory. In: PALIER, B. A long goodbye to Bismarck? The politics of welfare reforms in continental Europe. Amsterdam, NL: Amsterdam University Press, 2010.

PALIER, B.; MARTIN, C. From a 'frozen landscape' to structural reforms. The sequential transformations of Bismarckian welfare systems. In: PALIER, B.; MARTIN, C. Reforming the Bismarckian welfare system. Oxford, UK: Blackwell Publishing, 2008.

PIERSON, P. Increasing returns, path dependency and the study of politics. The American Political Science Review, Cambridge, v. 94, n. 2, p. 251-267, Jun.2000.

PIERSON, P. Post-industrial pressures on the mature welfare states. In: PIERSON, P. New politics of the welfare state. Oxford, UK: Oxford University Press, 2001.

POLANYI, K (1944). A grande transformação: as origens da nossa época. Rio de Janeiro, RJ: Campus, 2000.

QUADAGNO, J. Theories of the welfare state. Annual Review of Sociology, El Camino Way, v. 13, p. 109-128, Aug. 1987.

RHODES, M. Southern European welfare states: identity, problems and prospects for reform. In: RHODES, M. (Org.). Southern European welfare states: between crisis and reform. London, UK: Frank Cass and Co., 1997.

SAINSBURY, D. Introduction. In: SAINSBURY, D. (Org.). Gender and Welfare State Regimes. Oxford, UK: Oxford University Press, 2000.

STEPHENS, J. The Scandinavian welfare states: achievements, crisis and prospects. In: ESPING-ANDERSEN, G. Welfare states in transition. London, UK: Sage Publications, 1996.

TAYLOR-GOOBY, P. The impact of new social risks on welfare states. In: CONFERENCE OF ESPAnet, Copenhagen, 2003.

TITMUSS, R. (1963). Essays on "the welfare state”. $3^{\text {rd }}$ ed. London, UK: Allen \& UnWin, 1976.

TITMUSS, R. Social policy: an introduction. New York, US: Pantheon, 1974. 
TORRES FILHO, E. T. Entendendo a crise do "subprime". BNDES Visão do Desenvolvimento, n. 44, 18 jan. 2008.

VIEBROK, E.; CLASEN, J. Flexicurity: a state-of-the-art review. Working Papers on the Reconciliation of Work and Welfare in Europe. Edinburgo [s.n.], Jan. 2009. WEBER, M. The methodology of the social sciences. Illinois, US: The Free Press, 1949.

WILENSKY, H. The welfare state and equality: structural and ideological roots of public expend-itures. Berkeley, US: University of California Press, 1975.

WILSFORD, D. Path dependency, or why history makes it difficult but not impossible to reform health care systems in a big way. Journal of Public Policy, Cambridge, v. 14, n. 3, p. 251-283, Jul. 1994.

WOLF, P. J. W. Os Estados de Bem-Estar Social da Europa Ocidental: tipologias, fundamentos e evidências. 2015. 296f. Dissertação (Mestrado em Economia)Instituto de Economia da Universidade Estadual de Campinas, Campinas, 2015. 